Reihe Ökonomie Economics Series

\title{
Market Integration in Russia During the Transformation Years
}

Konstantin Gluschenko 
Reihe Ökonomie Economics Series

\section{Market Integration in Russia During the Transformation Years}

Konstantin Gluschenko

July 2002

Institut für Höhere Studien (IHS), Wien Institute for Advanced Studies, Vienna 


\section{Contact:}

Konstantin Gluschenko

Institute of Economics and Industrial Engineering

Siberian Branch of the Russian Academy of Sciences

Laventieva pr. 17

630090 Novosibirsk, Russia

潈: +7 (3832) 302548

fax: +7 (3832) 302580

email: glu@nsu.ru

Founded in 1963 by two prominent Austrians living in exile - the sociologist Paul F. Lazarsfeld and the economist Oskar Morgenstern - with the financial support from the Ford Foundation, the Austrian Federal Ministry of Education and the City of Vienna, the Institute for Advanced Studies (IHS) is the first institution for postgraduate education and research in economics and the social sciences in Austria. The Economics Series presents research done at the Department of Economics and Finance and aims to share "work in progress" in a timely way before formal publication. As usual, authors bear full responsibility for the content of their contributions.

Das Institut für Höhere Studien (IHS) wurde im Jahr 1963 von zwei prominenten Exilösterreichern dem Soziologen Paul F. Lazarsfeld und dem Ökonomen Oskar Morgenstern - mit Hilfe der FordStiftung, des Österreichischen Bundesministeriums für Unterricht und der Stadt Wien gegründet und ist somit die erste nachuniversitäre Lehr- und Forschungsstätte für die Sozial- und Wirtschaftswissenschaften in Österreich. Die Reihe Ökonomie bietet Einblick in die Forschungsarbeit der Abteilung für Ökonomie und Finanzwirtschaft und verfolgt das Ziel, abteilungsinterne Diskussionsbeiträge einer breiteren fachinternen Öffentlichkeit zugänglich zu machen. Die inhaltliche Verantwortung für die veröffentlichten Beiträge liegt bei den Autoren und Autorinnen. 


\section{Abstract}

A cross-sectional relationship between price dispersion among Russian regions and per capita income dispersion is used to measure the degree of integration between regional commodity markets. The sequence of cross-sectional estimations for each month of the period spanning 1992 through 2000 provides the temporal pattern of market integration in Russia, yielding an integration trajectory. This pattern suggests that the regional fragmentation of the national market had been increasing during the early years of transition, and then (since about the end of 1994) integration was tending - in general - to improve. However, substantial fluctuations occur in the movement to more integration. Difficult-toaccess regions markedly contribute to the overall disconnectedness of regional markets; controlling for these regions, the pattern becomes more encouraging. Surprisingly, the European part of Russia turns out to be less integrated than its Asian part. A number of culprits behind market fragmentation are found, organized crime among them.

\section{Keywords}

Market integration, law of one price, price dispersion, Russian regions

\section{JEL Classifications}

P22, R10, R15 


\section{Comments}

This work was supported by the Research Support Scheme of the Open Society Support Foundation, grant No.: 618/2000. The author is grateful to Dan Berkowitz, Michael Beenstock, and Mark Schaffer for helpful discussions. Thanks also to David Brown for providing me with some data. 


\section{Contents}

1. Introduction 1

2. Measuring market integration 2

3. Data and econometrics 5

4. Temporal pattern of integration 6

5. Role of the Non-traded Component 12

$\begin{array}{ll}\text { 6. A Comparison } & 18\end{array}$

7. Anatomy of Market Segmentation 20

8. Conclusions 25

$\begin{array}{ll}\text { References } & 26\end{array}$

$\begin{array}{lr}\text { Appendix } & 28\end{array}$ 


\section{Introduction}

The spatial behavior of prices in Russia has been dramatically changing in the course of transition. After the price-liberalization shock of 1992, prices sharply diverged across regions of the country, so indicating progressive regional fragmentation of the national market (see, e.g., Koen and Phillips, 1992). But in due course they started movement in the opposite direction. Considering price data for 1994, De Masi and Koen (1996) find the Russian market to be weakly integrated; however, the degree of integration seems to them to have increased by that time since 1992. In a more recent paper, Koen and de Masi (1997) state that price convergence across regions within a country over time is one of the stylized facts observed in most transitional economies.

Nevertheless, the pattern is rather erratic, since, on the other hand, there is abundant evidence that forces counteracting market integration - specifically, regional protectionism are strong enough. And so, the resulting tendency is vague. The aim of this paper is to obtain an evolving pattern of Russia's market integration from the beginning of the price liberalization till recent years.

To achieve this aim, a cross-sectional relationship between commodity price dispersion and demand dispersion (represented by per capita income dispersion) across Russian regions in some point in time is used. If the law of one price holds, i.e., the market is integrated, then a regional price should depend on the overall demand in the national market rather than on the local demand. Hence, controlling for transportation costs (proxied by inter-regional distances), this relationship should be statistically insignificant. Otherwise the strength of the relationship indicates the extent of deviation of the national market from complete integration. Running cross-sectional estimations for each available time point, an integration trajectory (i.e., a time series of the integration measure) is obtained, thus providing the temporal pattern of market integration. The cost of a uniform basket of basic food goods is used as a commodity price index. The data cover 74 regions in Russia, and span the period February 1992 through December 2000 with monthly frequency.

The results obtained suggest that regional fragmentation of the Russian market had been sharply increasing during the early years of transition, and then (since about the end of 1994) integration was tending - in general - to improve. However, substantial fluctuations occur in the movement to more integration. Using quite different methodology, Berkowitz and DeJong (2001) find a similar pattern of fluctuations during 1995 through 1999, the period covered by their analysis (a comparison is provided below in Section 6). Difficult-to-access regions markedly contribute to the overall disconnectedness of regional markets; controlling for these regions, the pattern becomes more encouraging. Surprisingly, the European part of Russia (without its northern territories) turns out to be less integrated than Siberia and Far East excluding difficult-to-access regions. 
The issue of market integration in contemporary Russia has been the subject of a number of studies. Gardner and Brooks (1994), De Masi and Koen (1996), and Goodwin et al. (1999) examined the early stage of transition. They found large price differences across locations that could not be assigned to transportation costs. At the same time, some indications were obtained that these differences tended to decrease. Covered a more long time span, results by Berkowitz et al. (1998) are resembling, indicating poor market integration in Russia as well, but they are somewhat better. More recently, Berkowitz and DeJong (1999) found a culprit behind the market fragmentation, the so-called Red Belt (a group of anti-reform regions). Gluschenko (2001a, 2002b) analyzed cointegration and threshold relationships for location pairs; the first study involved regions of Western Siberia (data spanning 1994-1998), and the second covered entire Russia (data spanning 1994-2001) with regions aggregated to economic territories, ekonomicheskiy rayon. The patterns obtained were mixed; both integrated and non-integrated location pairs were found, thus evidencing that the Russian market is not near to being completely integrated.

The papers cited use the same methodologies that are applied to spatially dispersed markets within countries with advanced market economies (see, e.g., Parsley and Wei, 1996; Engel and Rogers, 1996; Obstfeld and Taylor, 1997). A feature of these methodologies is that they yield estimates which average, in some sense, the price behavior over the entire period. Therefore the pattern of integration turns out to be static even though raw data are time series. This is of little importance if the case in hands is a stable economy, where the nature of price behavior does not sufficiently change with time. But it is in a transitional economy where such changes are to be expected. And they hold the greatest interest, characterizing the transitional process itself. This paper focuses just on changes in Russia's market integration rather than on its "temporally aggregated" state.

\section{Measuring market integration}

As it immediately follows from the law of one price, in a perfectly integrated economy, a regional price of a (tradable) good is determined in the national market, and does not depend on local demand. If the quantity demanded in the region increases or decreases (due to, e.g., changes in regional per capita income), then abitrageurs adjust the quantity supplied by moving the good to or from the region. This implies that the supply curve is absolutely elastic, $p_{r}\left(q_{r}\right)=p^{*}$ (=const), where $p_{r}$ is the price of the good in region $r, q_{r}$ is the quantity supplied, and $p^{*}$ is the national-market price, i.e., just the "one price".

To take it more formally, let us assume the income per capita, $i_{r}$, to be the only (in addition to price) determinant of demand, $q_{r}=D\left(p_{r}, i_{r}\right)$, and let $q_{r}=S\left(p_{r}\right)$ be the supply function. The regional price, $p_{r}$, is a solution of the equilibrium equation $D\left(p_{r}, i_{r}\right)=S\left(p_{r}\right)$; hence, $p_{r}=f\left(i_{r}\right)$. This function $f\left(i_{r}\right)$ can be represented as $k i_{r}^{\beta}$ (in particular, assuming the elasticity of demand 
on income to be constant). For convenience, the logarithmic representation is hereafter used, uppercase letters denoting logarithms of variables written in lowercase, e.g., $P_{r}=\ln p_{r}$. Then

$$
P_{r}=K+\beta I_{r}
$$

Since, by the law of one price, $P_{r}$ is always equal to $P^{*}$, it cannot depend on $I_{r}$; hence, $\beta=0$ should hold. Or, in econometric terms, allowing for random disturbances in the right-hand side of (1), $\beta$ should be statistically insignificant.

Subtracting Equation (1) for some region $s$ from that for $r$, the relationship rearranges to an equation in terms of percentage differentials $\left(P_{r s} \equiv P_{r}-P_{s}=\ln \left(p_{r} / p_{s}\right)\right.$; similarly for income):

$$
P_{r s}=\beta I_{r s}
$$

In this equation, the equality of $\beta$ to zero becomes quite obvious as it should be $P_{r s}=0$ under the law of one price.

Hence, relationship (1) or (2) can be used as a cross-sectional test for the law of one price. If $\beta=0$ holds over a set $\{r\}$ (or a pairwise set $\{(r, s)\}$ ), then the relevant market can be deemed as integrated. A non-zero value of $\beta$ (it is easily proved that $\beta$ should be positive in such a case) is a sign that regional markets are not perfectly integrated. Being the elasticity of price dispersion on income dispersion in Equation (2), the magnitude of $\beta$ can be used as a measure of the degree of market integration; the higher $\beta$, the weaker integration (thus, in fact, $\beta$ measures market fragmentation). ${ }^{1}$

In essence, the right-hand side of (2) evaluates the overall height of barriers to trade between regions $r$ and $s$. Let $C_{r s}$ represent costs needed to move a unit of the good from $s$ to $r\left(C_{r s} \equiv \ln \left(1+C_{r s}\right), C_{r s}\right.$ being arbitrage transaction costs expressed as a percentage of $\left.p_{r}\right)$. Then $P_{r}=P_{s}+C_{r s}$, and $P_{r s}=C_{r s}$. Assume that some components of $C_{r s}$ are quantifiable, thus providing an (unknown) portion $q \leq 1$ of the overall value of transaction costs. If the righthand side of (2) is augmented for $q C_{r s}$, the value of $\beta$ decreases, since $(1-q) C_{r s}=\beta I_{r s}$ with this. In the case that transaction costs are fully identified, that is $q=1$, we get $\beta=0$.

This provides a helpful framework for analyzing importance of various trading frictions at all. But one of them, the segmentation of markets by physical distance, is to be taken into account in all instances. The point is that the perfect integration is far from the case in the

\footnotetext{
${ }^{1}$ It is worth of note that $\beta=0$ is a necessary condition for the law of one price to hold, but it is not a sufficient condition. The point is that there may be forces causing regional prices to deviate from the equality regardless of local demands (incomes); sale taxes varying across regions provide an example.
} 
reality; e.g., Engel and Rogers (1996) as well as Parsley and Wei (1996) find price dispersion among US cities to depend strongly on distance. And so, it is reasonable to accept a more realistic benchmark of integration, allowing for "natural", irremovable impediments to inter-regional trade such as physical distances. ${ }^{2}$ That is, an economy is deemed to be (realistic) integrated if there are no "artificial" impediments only in it. Thus, the degree of integration, $\beta$, will be measured with arbitrage transaction costs reduced by transportation costs.

By assuming transportation costs to be log-linear function of distance, $C_{r s}^{(T)}=\alpha+\gamma L_{r s}$, the following equation is arrived at:

$$
P_{r s}=\alpha+\beta I_{r s}+\gamma L_{r s}
$$

where $L_{r s} \equiv \ln I_{r s} ; I_{r s}$ is distance separating regions $r$ and $s$. If arbitrage transaction costs are nothing but costs of shipping goods, i.e., $C_{r s}^{(T)}=C_{r s}$, then it will be $\beta=0$, and the market is recognized as integrated.

A caveat is that the price differential, $P_{r s}$, may pick up, along with the effect of impediments to trade, variations in income-dependent costs of non-traded component of the good. Costs of marketing and distribution in sale prices are meant. Since these services are highly laborintensive, their costs depend strongly on local wages in retail trade, and the wages, in turn, may be highly correlated with local per capita income. Then $\beta$ would capture a mixture of both the effects. There are two possible ways to deal with this problem. The first is to interpret the difference in distribution costs as an additional indication of imperfect integration. In fact, this means extending the notion of market integration. That is, $\beta$ will measure not only integration of the commodity market as such, but also integration of the market for distribution services and that of the retail-trade labor market. ${ }^{3}$ The second way is to explicitly take into account differences in distribution costs, supplementing the right-hand side of (3) with a relevant variable, or eliminating these costs from raw prices used to calculate $P_{r s}$.

Unfortunately, the latter way is not easy to follow, as statistical data on distribution costs or retail-wholesale margins are rather poor (not only in Russia, in other countries as well). That is why the first approach is used in this paper. Luckily, the effect of non-tradable inputs is not fundamental (at least, for Russia) as it follows from a below-presented comparison of estimations with and without distribution costs that are available on yearly base.

\footnotetext{
${ }^{2}$ In the case of Russia, there is one more "natural" impediment, namely, difficult access to a number of regions; see the next section.

${ }^{3}$ Such a generalization is quite meaningful, since distribution costs may not all be location-specific. For example, this is the case when there are nation-wide department store chains and corporations' distribution networks.
} 


\section{Data and econometrics}

A price index used for statistical analysis is the cost of the basket of 25 basic food goods accepted as standard by the Russian statistical agency, Goskomstat, during January 1997 through June 2000. Appendix Table A-1 provides the composition and the structure of the basket. The data are monthly, spanning the period February 1992 through December 2000 (107 months). They were obtained directly from Goskomstat's office (the index before 1997 was computed there to author's order; as for July to December 2000, Goskomstat still continued calculating this index though did not already publish it). The price data are for capital cities of Russian regions while income data are for regions; incomes are drawn from monthly statistical bulletin "Social and Economic Situation of Russia" for 1992-2000.

The basic spatial sample covers 74 regions in Russia (of all the 89). The data are lacking for 10 autonomous okrugs, Chechen Republic, Republic of Ingushetia, and the Jewish Autonomous Oblast. Besides that, the Moscow Oblast and the Leningrad Oblast are omitted because their capital cities, Moscow and St. Petersburg, are at the same time separate subjects of the Russian Federation reckoned among the 89 regions. Distances are mostly railroad ones except for a few for regions having no railway communication (highway, river or sea distance is taken in such a case). ${ }^{4}$

To estimate market integration at a time point (month) $t$, an econometric version of Equation (3) is used,

$$
P_{r s}(t)=\alpha(t)+\beta(t) I_{r s}(t)+\gamma(t) L_{r s}+\varepsilon_{r s}(t), \quad(r, s) \in \Pi \subset\left\{1, \ldots, N^{2},\right.
$$

where $\varepsilon_{r s}(t)$ is an error term, and $N$ is the number of regions. Regression (4) is estimated over a set $\Pi$ of dissimilar pairs of regions, that is, either pair $(r, s)$ or $(s, r)$ is included for given $r$ and $s ; r \neq s$. For simplicity, let this set be such that for each its pair $P_{r s}(t) \geq 0$.

Equation (4) is a cross-sectional regression. Running it sequentially for each available point in time, a time series of the integration measure is obtained, $\beta(t)$ for $t=1992: 02, \ldots, 2000: 12$, which provides the pattern of changes in integration during the period covered.

The basic spatial sample, hereafter referred to as "entire Russia", yields 2,701 (= 74×73/2) region pairs. Besides that, estimations are run over two more samples that are subsamples of the basic sample.

One of them represents Russia excluding difficult-to-access regions. This sample includes 69 regions generating 2,346 pairs. Excluded are the Murmansk Oblast, Republic of Sakha

\footnotetext{
${ }^{4}$ The distance matrix was compiled by Alexei Abramov, Novosibirsk State University.
} 
(Yakutia), the Sakhalin Oblast, the Magadan Oblast, and the Kamchatka Oblast. They are remote regions lacking (except the Murmansk Oblast) railway and highway communication with other regions. Due to this, arbitrage can hardly be bilateral there, goods being imported only to these regions. Obviously, difficult access to a number of regions worsens integration of the national market. And so, eliminating such regions is equivalent to controlling for this "natural" impediment to integration.

Another sample represents the European part of Russia excluding its northern territories; it is hereafter referred to as simply "European Russia". There are 51 regions in the sample, hence 1,275 region pairs. Since the transport infrastructure is more developed in this part of the country, and distances are shorter, one might a priori believe European Russia to be more integrated than the remainder of the country without difficult-to-access regions. Therefore it is interesting to verify whether such a belief is true.

There are missed observations on prices $p_{r}$ in the time series used. The gaps in the price data are especially numerous in the initial portion of the period covered, 1992-1994. For some months, data are lacking for up to 15 regions, reducing 1.6-fold the number of region pairs. To fill the gaps, missed prices are approximated, using regional monthly CPI-food. The interpolated value of $p_{r}(t)$ is the arithmetic mean of the nearest known preceding price inflated (through the chain method) to the required time point, $t$, and the nearest known succeeding price deflated to $t$. Let prices at $t-m$ and $t+n$ be known, and $\pi_{r}(\tau)$ be CPl-food for month $\tau$ in region $r\left(\pi_{r}(\tau)=\bar{p}_{r}(\tau) / \bar{p}_{r}(\tau-1)\right.$, where $\bar{p}_{r}(\cdot)$ is the overall level of prices for foodstuffs). Then the interpolated price is computed as

$$
p_{r}(t)=\frac{1}{2}\left(p_{r}(t-m) \cdot \pi_{r}(t-m+1) \cdot \pi_{r}(t-m+2) \cdot \ldots \cdot \pi_{r}(t)+\frac{p_{r}(t+n)}{\pi_{r}(t+n) \cdot \pi_{r}(t+n-1) \cdot \ldots \cdot \pi_{r}(t+1)}\right) .
$$

For example, if an observation for one month is missed, its restored value looks like $p_{r}(t)=$ $\left(p_{r}(t-1) \cdot \pi_{r}(t)+p_{r}(t+1) / \pi_{r}(t+1)\right) / 2$

\section{Temporal pattern of integration}

Having been obtained for each of 107 months, the results are too cumbersome to be tabulated. For this reason they are mostly presented in graphic form. At first it is useful to look at the evolution of inter-regional price volatility. Figure 1 plots standard deviations over region pairs of the price differential for each time point, $\sigma(t)=\sigma\left(P_{r s}(t)\right)$, and for the three region samples. Being calculated over a set of dissimilar region pairs, $\Pi, \sigma(t)$ would depend on choice of $\Pi$ that is arbitrary (averaging over various $\Pi$ produces different means, hence, standard deviations). To avoid such an ambiguity, the standard deviations in Figure 1 are calculated over the full set of region pairs, i.e., including both $(r, s)$ and $(s, r)$; in the case of 
entire Russia, this set contains $N(N-1)$ pairs. Since $P_{s r}=-P_{r s}$, the mean over such set of the price differential always is zero. ${ }^{5}$

From Figure 1 it is seen that the inter-regional volatility of prices was rising during the early years of the transition, and then it was almost permanently declining. Judging from this

Figure 1. Standard deviations of the price differential

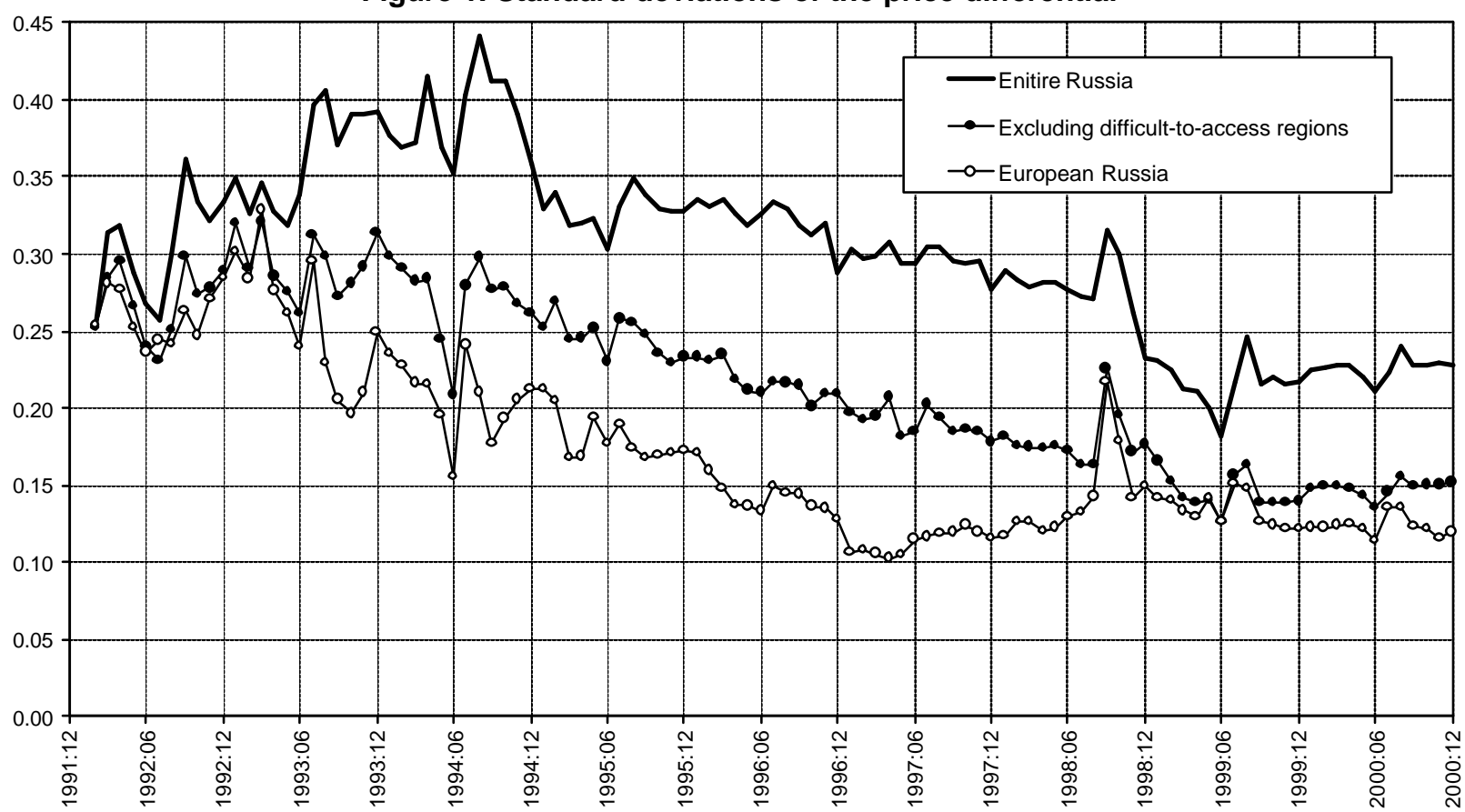

indirect evidence, one might expect a resembling dynamics of market integration - its deterioration in the initial stage of the market transformation, and its improvement with time after that. The price volatility over European Russia almost always is less than over other region samples. This seemingly corroborates the hypothesis of better integration in this part of the country. For comparison, appendix Figure A1 reports inter-regional volatility of incomes.

Let us turn now to the regression results. They are listed in appendix Table A-2. Figure 2 reports point estimates of $\beta(t)$ for various region samples. Recall that $\beta$ actually measures the degree of segmentation of a market, i.e., the zero level corresponds to complete integration, and the higher $\beta$, the lower integration. Appendix Figure A-2 plots estimates of $\gamma(t)$, and Figure A-3 plots the $R^{2}$ statistic for the regressions reported.

\footnotetext{
${ }^{5}$ Thus, the standard deviations plotted differ from those of the endogenous variable in the regressions. However, the difference is in numerical values rather than in the behavior of $\sigma(t)$ with time. Being plotted, $\sigma(t)$ over the actually used sets of pairs produces curves having almost the same shapes like in Figure 1.
} 
For entire Russia, all estimates of $\beta$ are highly statistically significant, having $p$-values less than 0.001 ; the same is true for distance. An exception is three estimates with slightly higher p-values, 0.002 to 0.006 . Except for 1992:02, where $\beta$ is insignificant, and 1993:03, where its $p$-value equals $0.029, \beta$ for Russia excluding difficult-of-access regions is significant at the 0.1 -percent level as well. There are two points in time where distance is insignificant over this sample (1992:03 and 1992:07). The remaining estimates of $\gamma$ are significant at the 0.1percent level except for the three with the 5-percent significance and one (1992:02) with the 10-percent significance. For European Russia, there are four insignificant estimates of $\beta$ in the initial part of the period (in 1992:02, 1992:03, 1993:02, and 1993:05), and four estimates are negative (in 1992:02, 1992:09, 1993:01, and 1993:03), of which three are significant. All remaining estimates of $\beta$ but a few ones are significant at the 0.1 -percent level. As for the coefficient on distance, it is rather small over European Russia, and not infrequently it becomes insignificant. Of all the 107 estimates of $\gamma, 30$ are insignificant, 9 are significant at the 10-percent level, 12 are significant at the 5-percent level, and the rest are significant at the 1-percent level (mostly, at the 0.1-percent level). Interestingly, beginning from 1998:12, distance becomes almost permanently insignificant in European Russia.

During the early years following the price liberalization, fragmentation of the Russian market was sharply increasing. In fact, the market was changing into a collection of loosely bound regional markets. However, caution is required in the interpretation of results for the very initial part of that period, the first few months of 1992. It is unlikely that the rise of $\beta$ at that time reflects deterioration of market integration. Judging from the value of $\beta$, the Russian market was almost "perfectly integrated" at the starting point, the beginning of 1992. With centralized pricing, prices, indeed, in no way depend on demand; hence we will inevitably obtain $\beta=0$. But this bears no relation to market integration; the notion itself is meaningless in such a situation, as there is no market at all. And the price liberalization did proceed gradually to some extent. Namely, for a number of goods, the freedom of pricing was restricted to certain limits that were subsequently widened or removed; for details, see Frenkel' (1997) and Serova (2000). This concerns basic goods, many of which just enter into the basket of 25 food goods. Moreover, neither producers nor wholesale and retail traders initially had experience of pricing on their own, and this might cause rather weak (if any) linkage between prices and demand.

Turning back to Figure 1, we see that the inter-regional volatility of prices was not too low in the first months of 1992. But the regression results indicate weak or no dependence of price dispersion on distance in these months. Hence, the law of one price hardly held, even being treated accurate to transportation costs. It seems likely that it is just the case mentioned in the footnote 1 , where price dispersion is caused mostly by various accidental reasons exhibiting no any regularity, and so, violation of the law cannot be captured or is understated by the regression implemented. 
Probably, the fast rise of $\beta$ (strengthening dependence of prices on local demand) in the early months of the market reforms was induced by the adaptation of sellers to market pricing and by widening its scope. But the possibility itself of such a dependence results from weakness of inter-regional trade relations, which keeps price disparities from elimination. Thus the beginning of the integration trajectories provides only indirect evidence that the degree of integration of the Russian market was low at that time, but it gives no idea of the actual value of this degree. Thereafter the value of $\beta$ was being progressively more determined by the magnitude of impediments to inter-regional trade, while the component conditioned by the transition from planned to market pricing was gradually decreasing in importance until vanished at all. There is no way to recognize how long time this component existed and what was its contribution to the value of $\beta$ at particular points in time. It may be only supposed, based upon observations of the reality of that time, that as early as mid-1993 its role, probably, was of little importance.

And so, subsequent values of $\beta$ entirely owe their rise to increasing economic isolation of regions. In the early years of the transition, there were only embryos of market institutions, hence prerequisites to inter-regional arbitrage were simply lacking. The overwhelming share of both retail and wholesale trade still remained to be state-run, having neither the stimuli nor the possibilities for arbitrage. There were private firms and individuals that did practice spatial commodity arbitrage, but these were very small firms at that time, and their contribution to the total volume of trade was minor. Trade flows between regions were chaotic, accidental bargains prevailing (the more so as information on arbitrage opportunities was almost entirely lacking). Regional authorities were contributing largely to economic separation of regions, aiming to cushion price shocks in their own regions. Numerous regional programs of the "food security" (that is, the selfprovision of a given region with foodstuffs) were developed in the early years of the reforms, so pushing regions to the autarky.

Segmentation of the Russian market peaked in 1993-1994. However, by 1994, a foundation of market institutions in the Russian consumer market apparently came into being. And as market institutions were forming, wholesale and retail trade were being privatized, market infrastructure was developing, and "market mentality" was strengthening, the arbitrage activity was broadening. As a result, the improvement in market integration started from the end of 1994. This tendency remains valid till the very end of the covered period. In the last two years, 1999-2000, the value of $\beta$ ranges between 0.10 and 0.13 for entire Russia, and between 0.05 and 0.07 for Russia without difficult-to-access regions.

At the same time, deviations fom this tendency occur. For example, a fluctuation in the second half of 1995 was caused, probably, by a new wave of administrative trade barriers. They were local restrictions on exportation products outside regions, aiming to force agricultural firms located in a given region to pay debts to the regional budget (Serova, 2000). One more peak is induced by the financial crisis in August 1988. Interestingly, this 
peak is clear on the trajectories for Russia excluding difficult-to-access regions and European Russia, but it is not seen on the trajectory for entire Russia.

Returning to the early years of the transition, two time intervals of a sufficient improvement in integration are seen, approximately first halves of 1993 and 1994 . They roughly correspond to the intervals when the rise in food prices reduced dramatically (for example, from $29.0 \%$ in January 1993 to 16.1 in April 1993). Some changes in integration in those years might be assigned to variations in speed of change in the US dollar/ruble exchange rate. Appendix Figure A-4 gives an illustration. However, the relation between changes in integration and changes in inflation (as to foodstuffs) is far from unambiguous (the more so for the dollar/ruble exchange rate). Besides that, it is unclear what is the cause and what is the effect - whether inflation affects the integration or vice versa. Overall, the general view of the integration trajectories provides an impression of undulatory changes with yearly waves having the crest in the second half of a year, and the trough in the first half. Are there some regular reasons behind this, or is it nothing more than an accidental coincidence, that is the open question.

From comparison of the integration trajectories for Russia with and without difficult-to-access regions, it is apparent that these regions account for a significant share of the overall disconnectedness of regional markets in Russia. Eliminating these regions, the value of $\beta$ is approximately halved. Due to existence of regions with difficult access to them, the Russian market cannot become completely integrated during any foreseeable time, be the Russian economy as advanced market economy as wished. Hence, this geographical feature of the country should be taken into account while comparing integration in Russia with that in established market economies.

Another comparison involves Russia excluding difficult-to-access regions and the European part of the country without northern territories of this part. As mentioned above, European Russia might be expected to be more integrated. But surprisingly, this is not the case. Since the second half of 1995, values of $\beta$ are permanently higher here than in Russia without difficult-to-excess regions, up to almost two times in 2000 , when they are very close to the values for entire Russia. This implies that the market of European Russia is, vice versa, less integrated than the market of Siberia and Far East (excluding Yakutia, Sakhalin, Kamchatka, and the Magadan Oblast). Indeed, not reported estimates of $\beta$ for the latter are almost all insignificant since December 1998, suggesting that the relevant part of the national market is completely integrated in the last two years. Taking into consideration long distances between regions and relatively poor transport infrastructure there, this result is quite unexpected.

One of culprits behind weakening market integration in European Russia is the Moscow market. There is abundant evidence that sellers from other regions have no freedom of entry into this market; almost insurmountable barrier is erected here by both local "mafias" and the Moscow government - see, e.g., Berkowitz et al. (1998). Controlling for this culprit, values of 
$\beta$ fall dramatically while values of $\gamma$ rise (so indicating that transportation costs do matter in the European part of Russia). For example, $\beta$ decreases 1.3 to 2.6-fold in 2000, and $\gamma$ increases 1.3 up to 8 fold. Nevertheless, in so doing $\beta$ s do not become insignificant, still exceeding those for Asian Russia without its difficult-to-excess regions. Appendix Figure A-5, (a) and (b), gives an idea of impact of the Moscow market on estimates of $\beta$ and $\gamma$ for European Russia as well as a comparison with the values for Asian Russia.

As pointed out in Section 3, a portion of the price data consists of approximated values. To verify whether this considerably affects the behavior of the trajectories, regression (4) was also estimated over the source data set with gaps. This yielded only minor quantitative changes in the estimation results, and the trajectories remained to qualitatively be almost the same. As an illustration Figure 2 provides a comparison of trajectories for entire Russia obtained with and without filling the data gaps; appendix Figure A-6 does this for the rest two subsamples. Besides the CPI-based method of restoring missed observations by Formula (5), the linear interpolation was also tried. This method did not produce sufficient changes as well.

Figure 2. Integration trajectories

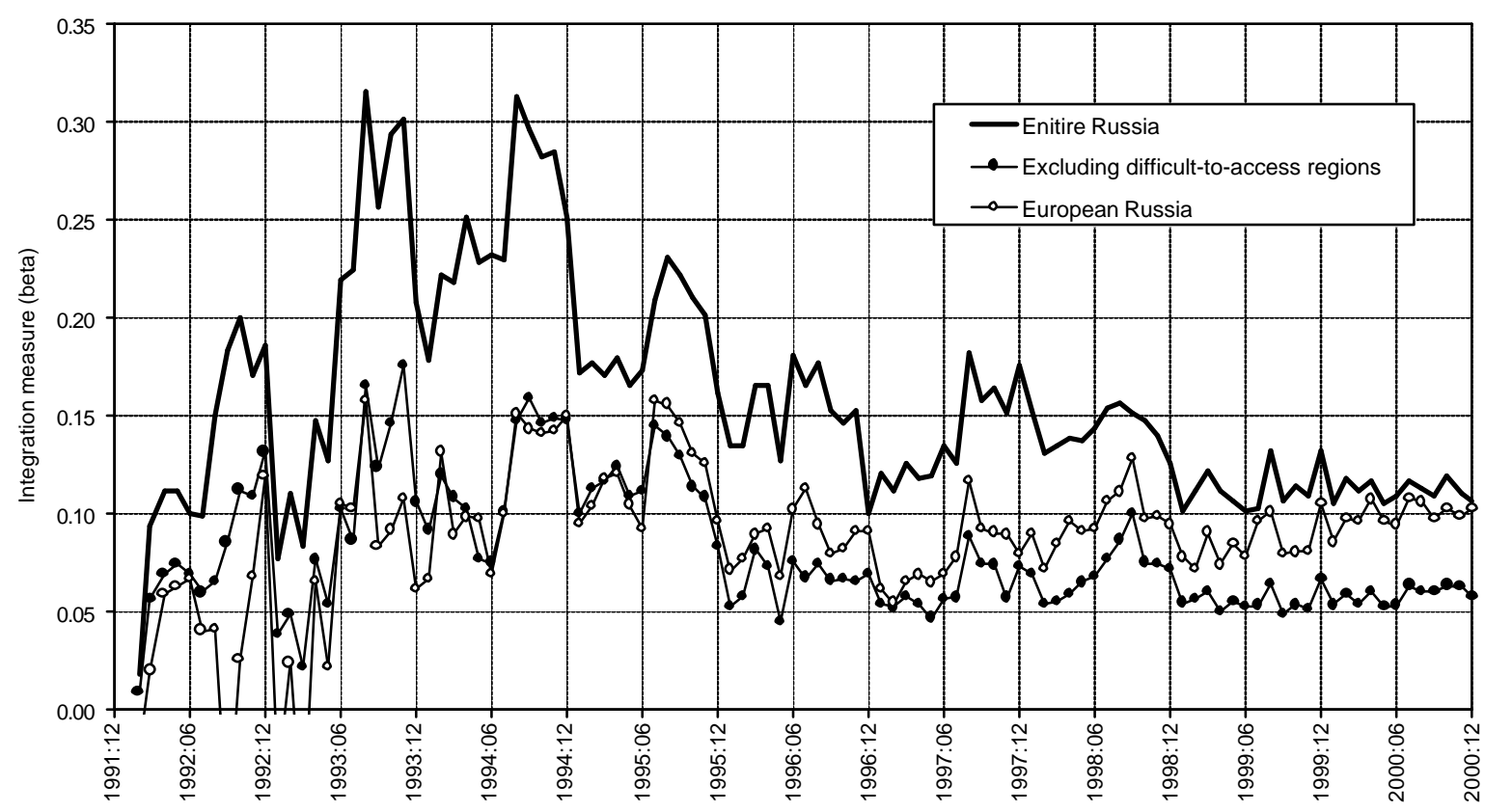


Figure 3. Impact of filling the data gaps on the trajectory for entire Russia

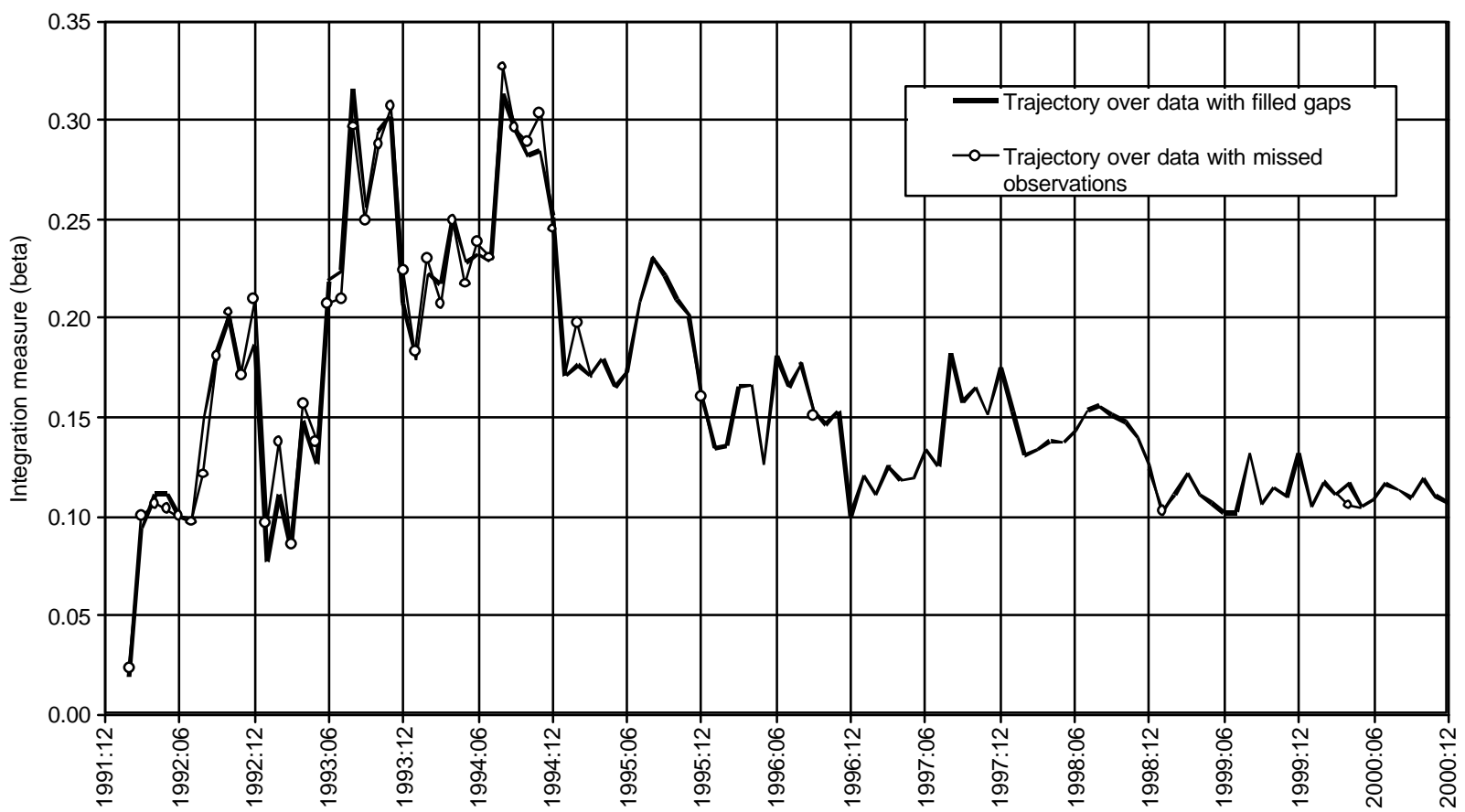

\section{Role of the Non-traded Component}

Another issue to be verified is that of the part played by the non-tradable component of goods in integration measure $\beta$. Data on regional wholesale prices for individual goods (and cost of the 25-item basket) as well as on structure of individual retail prices are not available. However, the Russian statistics observes aggregated trade indicators which can be used as proxies. These are trading costs relative to retail sales, and the net revenue calculated as the difference of sale proceeds and purchase value of goods; the indicators are computed over large and medium shops by region. If for no other reason than these indicators cover both foods and industrial goods, they provide very rough approximation for the food basket used. Nevertheless, they work. Both the indicators were tried, the first as a proxy of dstribution costs, and the second as a proxy of retail-wholesale margin, having yielded similar results. And so, only the former is considered below, being denoted $d_{r}$. The sources of the data are Goskomstat (1996b) and Goskomstat (1998). The data for 1992 and 1998-2000 are lacking; values of $d_{r}$ for 1997 are extended to $1998-2000 .^{6}$

Taking into account (percentage) distribution costs, the spatial equilibrium condition becomes:

$$
p_{r}\left(1-d_{r}\right)=p_{s}\left(1-d_{s}\right)\left(1+c_{r s}\right)
$$

\footnotetext{
${ }^{6}$ For these years, Goskomstat of Russia published the both indicators in monetary terms only without providing retail sales over large and medium shops to calculate the percentage.
} 
Table 1. Impact of distribution costs on estimates of the integration measure

\begin{tabular}{|c|c|c|c|c|c|c|c|}
\hline \multirow[t]{2}{*}{ Year } & \multirow[t]{2}{*}{ Variable } & \multicolumn{2}{|c|}{ Entire Russia } & \multicolumn{2}{|c|}{$\begin{array}{l}\text { Excluding difficult-to- } \\
\text { access regions }\end{array}$} & \multicolumn{2}{|c|}{ European Russia } \\
\hline & & Model 1 & Model 2 & Model 1 & Model 2 & Model 1 & Model 2 \\
\hline 1992 & $\begin{array}{l}\text { Income } \\
\text { Distance }\end{array}$ & $\begin{array}{l}0.141 \\
(0.008) \\
0.032^{* * *} \\
(0.003)\end{array}$ & NA & $\begin{array}{l}0.078 \\
(0.008) \\
0.013^{* * *} \\
(0.003)\end{array}$ & NA & $\begin{array}{l}0.034 \\
(0.013) \\
0.015^{\star * \star} \\
(0.005)\end{array}$ & NA \\
\hline 1993 & $\begin{array}{l}\text { Income } \\
\text { Distance } \\
\text { DC }\end{array}$ & $\begin{array}{l}0.203 \\
(0.010) \\
0.077^{\star * \star} \\
(0.004)\end{array}$ & $\begin{array}{l}0.171 \\
(0.010) \\
0.064^{\star * *} \\
(0.004)^{* * *} \\
0.364^{* k} \\
(0.034)\end{array}$ & $\begin{array}{l}0.087 \\
(0.009) \\
0.050^{\star * *} \\
(0.004)\end{array}$ & $\begin{array}{l}0.084 \\
(0.009) \\
0.047^{* * *} \\
(0.004) \\
0.120^{* * *} \\
(0.039)\end{array}$ & $\begin{array}{l}0.065 \\
(0.015) \\
0.010 \\
(0.007)\end{array}$ & $\begin{array}{l}0.067 \\
(0.015) \\
0.009 \\
(0.007) \\
0.101 \\
(0.082)\end{array}$ \\
\hline 1994 & $\begin{array}{l}\text { Income } \\
\text { Distance } \\
\text { DC }\end{array}$ & $\begin{array}{l}0.265 \\
(0.009) \\
0.123^{\star * *} \\
(0.004)\end{array}$ & $\begin{array}{l}0.242 \\
(0.009) \\
0.109^{* *} \\
(0.004)_{*} \\
0.250 \\
(0.017)\end{array}$ & $\begin{array}{l}0.124 \\
(0.007))_{*} \\
0.077^{* *} \\
(0.004)\end{array}$ & $\begin{array}{l}0.121 \\
(0.007) \\
0.072^{* *} \\
(0.004)^{*} \\
0.138 \\
(0.023)\end{array}$ & $\begin{array}{l}0.130 \\
(0.009) \\
0.024^{* *} \\
(0.004)\end{array}$ & $\begin{array}{l}0.133 \\
(0.009) \\
0.024^{* *} \\
(0.004) \\
0.107^{* *} \\
(0.035)\end{array}$ \\
\hline 1995 & $\begin{array}{l}\text { Income } \\
\text { Distance } \\
\text { DC }\end{array}$ & $\begin{array}{l}0.201 \\
(0.007) \\
\left.0.110^{*}\right) \\
(0.003)\end{array}$ & $\begin{array}{l}0.175 \\
(0.006) \\
0.080^{* *} \\
(0.003) \\
0.501^{* * *} \\
(0.025)\end{array}$ & $\begin{array}{l}0.125 \\
(0.006) \\
0.073^{* \star} \\
(0.003)\end{array}$ & $\begin{array}{l}0.122 \\
(0.006) \\
0.065^{* *} \\
(0.003) \\
0.230^{* * *} \\
(0.029)\end{array}$ & $\begin{array}{l}0.135 \\
(0.007) \\
0.013^{\star * *} \\
(0.004)\end{array}$ & $\begin{array}{l}0.134 \\
(0.007) \\
0.013^{*} \\
(0.004) \\
-0.051 \\
(0.045)\end{array}$ \\
\hline 1996 & $\begin{array}{l}\text { Income } \\
\text { Distance } \\
\text { DC }\end{array}$ & $\begin{array}{l}0.161 \\
(0.007) \\
0.13)_{* *} \\
(0.003)\end{array}$ & $\begin{array}{l}0.143 \\
(0.007) \\
0.098^{* * *} \\
(0.004) \\
0.467^{* * *} \\
(0.024)\end{array}$ & $\begin{array}{l}0.075 \\
(0.005) \\
0.077^{* *} \\
(0.003)\end{array}$ & $\begin{array}{l}0.076 \\
(0.006) \\
0.068^{* * *} \\
(0.003) \\
0.196^{* * *} \\
(0.021)\end{array}$ & $\begin{array}{l}0.096 \\
(0.005) \\
0.008 \\
(0.003)\end{array}$ & $\begin{array}{l}0.111 \\
(0.006) \\
0.006^{\star *} \\
(0.003) \\
0.185^{\star *} \\
(0.025)\end{array}$ \\
\hline 1997 & $\begin{array}{l}\text { Income } \\
\text { Distance } \\
\text { DC }\end{array}$ & $\begin{array}{l}0.147 \\
(0.007) \\
0.135^{* k *} \\
(0.003)\end{array}$ & $\begin{array}{l}0.140 \\
(0.006) \\
0.095^{* *} \\
(0.003) \\
0.480^{* *} \\
(0.019)\end{array}$ & $\begin{array}{l}0.066 \\
(0.005) \\
0.07)^{* *} \\
(0.003)\end{array}$ & $\begin{array}{l}0.074 \\
(0.005) \\
0.065^{\star *} \\
(0.003) \\
0.241^{\star *} \\
(0.017)\end{array}$ & $\begin{array}{l}0.085 \\
(0.004) \\
0.008^{* k} \\
(0.002)\end{array}$ & $\begin{array}{l}0.094 \\
(0.005) \\
0.007^{\star *} \\
(0.002) \\
0.121^{\star *} \\
(0.020)\end{array}$ \\
\hline 1998 & $\begin{array}{l}\text { Income } \\
\text { Distance } \\
\text { DC }\end{array}$ & $\begin{array}{l}0.152 \\
(0.007) \\
0.106^{\star * \star} \\
(0.003)\end{array}$ & $\begin{array}{l}0.151 \\
(0.006) \\
0.074^{* * *} \\
(0.003) \\
0.384^{* * *} \\
(0.019)\end{array}$ & $\begin{array}{l}0.076 \\
(0.005)^{\star \star \star} \\
0.046 \\
(0.002)\end{array}$ & $\begin{array}{l}0.080 \\
(0.005) \\
0.040^{* * *} \\
(0.003) \\
0.107^{* *} \\
(0.016)\end{array}$ & $\begin{array}{l}0.108 \\
(0.005) \\
0.007^{\star} \\
(0.003)\end{array}$ & $\begin{array}{l}0.113 \\
(0.005) \\
0.006^{\star \star} \\
(0.003) \\
0.073^{\star \star \star} \\
(0.025)\end{array}$ \\
\hline 1999 & $\begin{array}{l}\text { Income } \\
\text { Distance } \\
\text { DC }\end{array}$ & $\begin{array}{l}0.119 \\
(0.005) \\
0.065^{* * *} \\
(0.003)\end{array}$ & $\begin{array}{l}0.110 \\
(0.005) \\
0.046^{* * *} \\
(0.003) \\
0.260^{* * *} \\
(0.014)\end{array}$ & $\begin{array}{l}0.059 \\
(0.004) \\
0.018 \\
(0.002)\end{array}$ & $\begin{array}{l}0.060 \\
(0.005) \\
0.016^{* *} \\
(0.002) \\
0.056^{* *} \\
(0.013)\end{array}$ & $\begin{array}{l}0.093 \\
(0.005) \\
-0.006 \\
(0.003)\end{array}$ & $\begin{array}{l}0.097 \\
(0.005) \\
-0.005 \\
(0.003) \\
0.061 \\
(0.027)\end{array}$ \\
\hline 2000 & $\begin{array}{l}\text { Income } \\
\text { Distance } \\
\text { DC }\end{array}$ & $\begin{array}{l}0.116 \\
(0.005) \\
0.088^{\star * t} \\
(0.003)\end{array}$ & $\begin{array}{l}0.110 \\
(0.005) \\
0.069^{* *} \\
(0.003) \\
0.246^{* *} \\
(0.014)\end{array}$ & $\begin{array}{l}0.061 \\
(0.004) \\
0.037^{\star \star *} \\
(0.002)\end{array}$ & $\begin{array}{l}0.062 \\
(0.004)_{*} \\
0.034^{* *} \\
(0.002)^{*} \\
0.060^{* *} \\
(0.013)\end{array}$ & $\begin{array}{l}0.106 \\
(0.004) \\
-0.001 \\
(0.003)\end{array}$ & $\begin{array}{l}0.109 \\
(0.005) \\
-0.001 \\
(0.003) \\
0.044 \\
(0.021) \\
\end{array}$ \\
\hline
\end{tabular}

Notes: $\mathrm{DC}=$ distribution costs differential. The White heteroscedastic-consistent errors are in parentheses; "**, , , and ${ }^{*}$ denote significance at the $1 \%, 5 \%$, and $10 \%$ levels. 
Recall that $c_{r s}$ is percentage arbitrage transaction costs; for simplicity, the mark-ups in $r$ and $s$ are assumed to be equal. ${ }^{7}$ Hence, the right-hand side of (3) and (4) should be supplemented with variable $D_{r s}=\ln \left(\left(1-d_{s}\right) /\left(1-d_{r}\right)\right)$, which represents the distribution costs dispersion among regions (n the form of the percentage differential). Theoretically, the coefficient on this variable must equal 1. However, as a mere proxy is used instead of the true value of $D_{r s}$, the coefficient on it may sufficiently deviate from the theoretical value. Thus, the only thing to be expected is the positive sign of the coefficient.

Since only yearly data on distribution costs are available, other variables are temporally aggregated to be yearly ones too. Namely, they are averaged over year. Table 1 sets out estimation results without and with taking distribution costs into account. For brevity, the income differential is referred to as simply "Income"; Model 1 means specification (4), and Model 2 means (4) supplemented with variable $D_{r s}(t), t$ indexing years.

But for two instances, distribution costs are statistically significant and have the expected positive sign. However, the comparison of the integration measure estimates obtained in Model 1 and Model 2 suggests that changes in them caused by the inclusion of distribution costs are rather small. The coefficients on income in each pair of the models have overlapping 95-percent confidence intervals (except for entire Russia in 1995, where this is the 90-percent interval), thus indicating that the difference between the coefficients is hardly significant. The standard errors of $\beta$ remain almost the same, and do not change at all statistical inference about $\beta$. Here from it may be believed that the regressors $\mathbf{I}$ and $\mathbf{D}$ are near to be orthogonal, and that the omission of $\mathbf{D}$ biases the estimation of the regression variance only slightly.

Figure 4 provides a pictorial rendition of changes in the integration measure producing by taking distribution costs into account. 
Figure 4. "Aggregated" integration trajectories

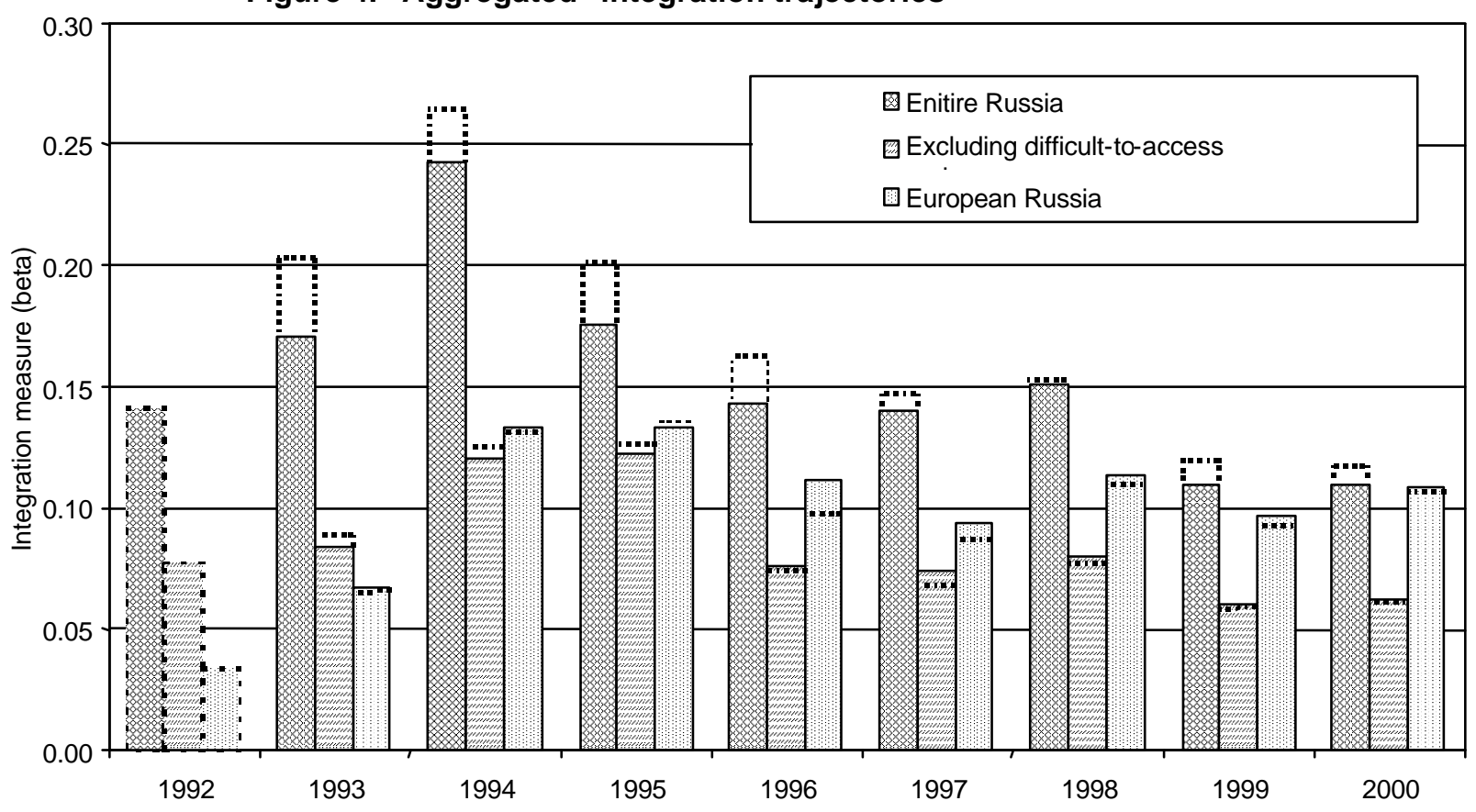

Note: The dashed lines mark the levels of $\beta$ obtained without regard for distribution costs.

The changes in estimation results are reported more fully in appendix Figure A-7. Comparing Figure 4 with Figure 2, it is seen that the yearly averaging does not distort the general evolution pattern. Losing details, the "aggregated" trajectories retain the main features of the evolution of market integration.

Dealing with entire Russia, the inclusion of distribution costs lowers $\beta$, as would be expected. But this not always is the case with Russia excluding difficult-to-access regions; beginning in 1996, $\beta$ increases in Model 2. The more so, when the case in hand is European Russia; here is the only instance of decreasing $\beta$. The effect of distribution costs on the coefficient on distance is stronger. When the difficult-to-access regions are present in the sample, the 95percent (as well as the 90-percent) confidence intervals of $\gamma$ do not overlap. However, they do for the other two samples. Values of $\gamma$ always fall with inserting distribution costs (though, sometimes remaining unchanged in European Russia).

Let us turn to the importance of distribution costs as compared to income and distance in determining price dispersion, measuring the importance of a variable as the contribution of its average value to the average price dispersion. As seen from (2) and (3), the intercept in regression (4) is nothing but a scaling multiplier for distance. Hence, the contribution of distance is $(\alpha+\hat{\gamma} L) / P$; for the other two variables, it is simply $\beta I / P$ and $\delta D / P$, where $\delta$ is the coefficient on the distribution costs differential. Table 2 reports these contributions rounded off to integer percents. (The input data are reported in the appendix; 
its Table A-3 lists the means of $P, I$, and $D$, and Table A-4 lists the estimated intercepts as well as mean distances.)

As figures from Table 2 evidence, the overwhelming share of price dispersion owes its origin to distance. Along with this, the economic significance of other impediments to arbitrage represented by the effect of income dispersion is high enough. This variable accounts for 10 to $20 \%$ of the average price dispersion (sometimes, even for more). At last, the contribution of the distribution costs dispersion is considerable over entire Russia; it markedly falls when the difficult-to-access regions are removed from the region sample, and becomes practically insignificant in European Russia. Comparing results for Model 1 and those for Model 2, we notice that the most share of the distribution costs contribution appears at a sacrifice of reducing the distance contribution, while the contribution of the income dispersion is little changed.

The explanation may be the expensiveness of marketing and distribution services in the remote, difficult-to-access regions. As distances to them are long too, this causes a (spurious?) correlation between distribution costs and distance. To a less degree the same is valid for Russia excluding difficult-to-access regions, as there are Siberian and Far-Eastern regions in the sample. 
Table 2. Contribution of variables to average price dispersion, percent

\begin{tabular}{|c|c|c|c|c|c|c|c|}
\hline \multirow[t]{2}{*}{ Year } & \multirow[t]{2}{*}{ Variable } & \multicolumn{2}{|c|}{ Entire Russia } & \multicolumn{2}{|c|}{$\begin{array}{l}\text { Excluding difficult-to- } \\
\text { access regions }\end{array}$} & \multicolumn{2}{|c|}{ European Russia } \\
\hline & & Model 1 & Model 2 & Model 1 & Model 2 & Model 1 & Model 2 \\
\hline \multirow[t]{2}{*}{1992} & Income & 14 & $\mathrm{NA}$ & 7 & NA & 1 & NA \\
\hline & Distance & 86 & & 93 & & 99 & \\
\hline \multirow{3}{*}{1993} & Income & 21 & 18 & 7 & 7 & 3 & 3 \\
\hline & Distance & 79 & 75 & 93 & 91 & 97 & 97 \\
\hline & DC & & 7 & & 2 & & 0 \\
\hline \multirow{3}{*}{1994} & Income & 32 & 29 & 14 & 14 & 15 & 15 \\
\hline & Distance & 68 & 64 & 86 & 83 & 85 & 85 \\
\hline & DC & & 7 & & 3 & & 0 \\
\hline \multirow{3}{*}{1995} & Income & 27 & 23 & 17 & 16 & 19 & 19 \\
\hline & Distance & 73 & 66 & 83 & 81 & 81 & 81 \\
\hline & DC & & 11 & & 3 & & 0 \\
\hline \multirow{3}{*}{1996} & Income & 20 & 18 & 9 & 9 & 14 & 16 \\
\hline & Distance & 80 & 65 & 91 & 85 & 86 & 83 \\
\hline & $\mathrm{DC}$ & & 17 & & 6 & & 1 \\
\hline \multirow{3}{*}{1997} & Income & 19 & 18 & 9 & 10 & 17 & 18 \\
\hline & Distance & 81 & 62 & 91 & 81 & 83 & 83 \\
\hline & $\mathrm{DC}$ & & 20 & & 9 & & -1 \\
\hline \multirow{3}{*}{1998} & Income & 22 & 22 & 12 & 13 & 20 & 21 \\
\hline & Distance & 78 & 62 & 88 & 83 & 80 & 80 \\
\hline & DC & & 16 & & 4 & & -1 \\
\hline \multirow{3}{*}{1999} & Income & 21 & 19 & 10 & 10 & 18 & 18 \\
\hline & Distance & 79 & 69 & 90 & 88 & 82 & 83 \\
\hline & $\mathrm{DC}$ & & 12 & & 2 & & -1 \\
\hline \multirow{3}{*}{2000} & Income & 20 & 19 & 11 & 11 & 24 & 25 \\
\hline & Distance & 80 & 69 & 89 & 87 & 76 & 75 \\
\hline & DC & & 12 & & 2 & & 0 \\
\hline
\end{tabular}

Note: $\mathrm{DC}=$ distribution costs differential.

Thus, the difference in distribution costs is responsible for some share of price dispersion. However, in the absence of a relevant variable in the regression, the most portion of its role is picked up by the distance variable, so preventing a considerable bias of $\beta$. Hence, it is possible to dispense with taking distribution costs into account (at least, while analyzing the Russian market). Some minor details of the qualitative pattern of the price behavior may be lost, but it will essentially be similar. 


\section{A Comparison}

It is interesting to correlate the pattern reported with results obtained with the use of an alternative methodology. Berkowitz and DeJong (2001) examined market integration in Russia, having used the same sample of 74 regions and the same price index as in this study.

The intuition behind their work is as follows. Price dispersion is assumed to fluctuate within bounds dictated by arbitrage transaction costs, $-C_{r s} \leq P_{r s}(t) \leq C_{r s}$. Hence, its temporal volatility calculated as the standard deviation of $P_{r s}(t)$ over a sub-period $t-n, \ldots, t+n, \sigma_{r s}(t)$, should be a function of $C_{r s}$ (implicitly assuming $C_{r s}$ to be near-constant during the subperiod). In turn, if a market is integrated then arbitrage transaction costs are nothing but transportation costs; thus, $\sigma_{r s}(t)$ should be an increasing function of distance. Basing on this, region $r$ is deemed to be integrated during a given sub-period when the coefficient on distance in the test regression of $\sigma_{r s}(t)$ on $L_{r s}$ (across $s$ ) is positive and statistically significant. The extent of market integration is measured as the percentage of integrated regions. Shifting $t$ - the median date of the twelve-month sub-period, $2 n=12-$ by monthly steps, the integration trajectory is obtained.

Figure 5 provides a comparison of the Berkowitz-DeJong integration trajectory with the trajectory for entire Russia from Figure 2 of this paper. The latter is turned over (since $\beta$ and the percentage of integrated regions change in opposite directions with an improvement in integration) and is vertically shifted in order to somehow match the trajectories. Certainly, they cannot coincide in any case, if for no other reason than the "integration percentage" is confined between 0 and 1 , while $\beta$ changes from 0 , having no upper bound. Nevertheless, the trajectories have much in common. 
Figure 5. Comparison of integration trajectories with different integration measures

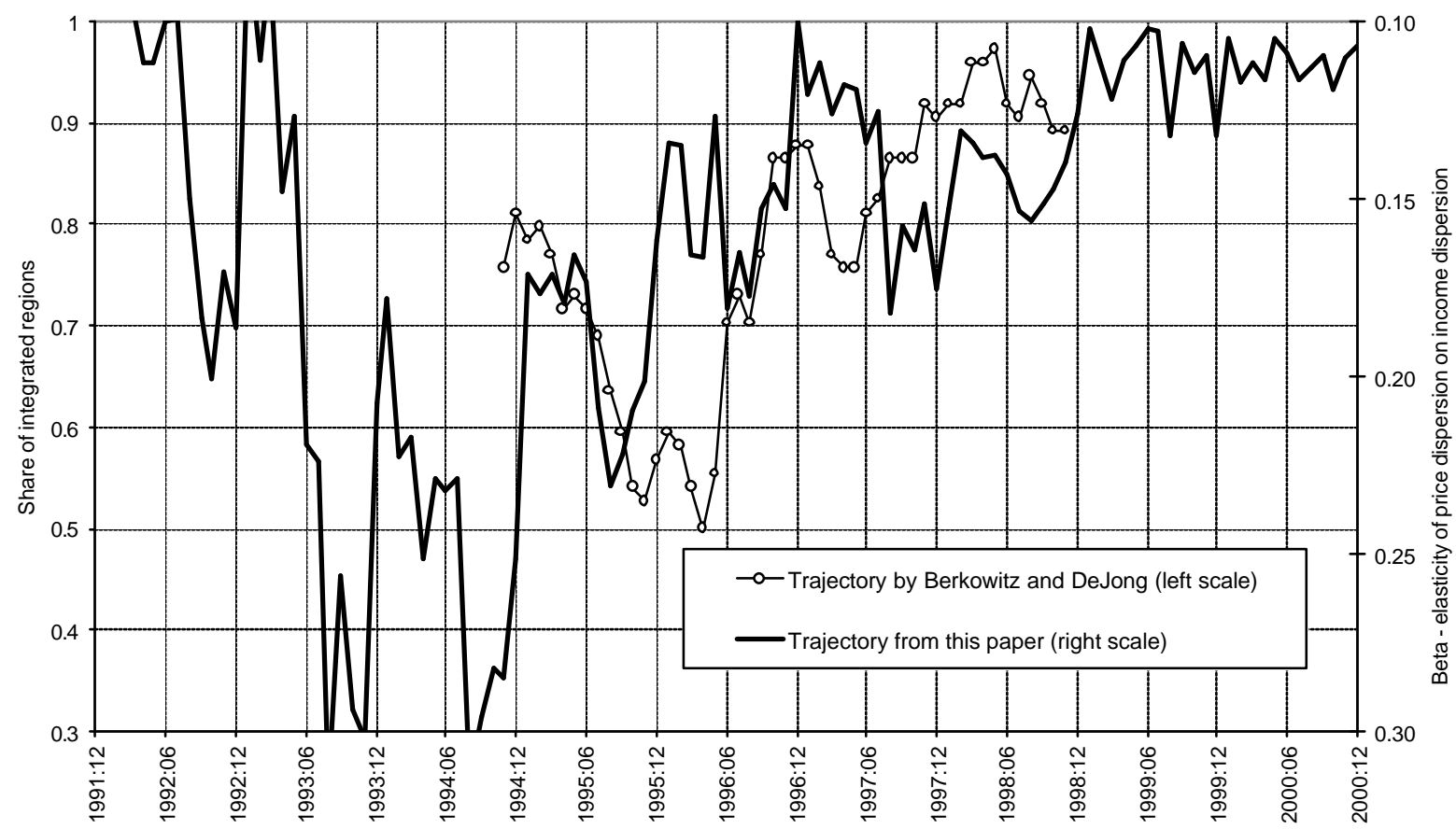

Roughly, the trajectories are alike in shape, having ups and downs in the same or neighboring points in time. With this, it should be noted that that the Berkowitz-DeJong trajectory is to some extent ambiguously related to the time scale. First, being the sixth month within a twelve-month interval over which the price volatility is calculated, their time point is not the exact median date; the seventh month could be equally well taken as a representative of the time interval. Second, the integration measure by Berkowitz and DeJong picks up the behavior of prices not only at a given point in time, but in its 5-6-month neighborhood as well. And this may cause a shift of a captured change in integration - as compared with the trajectory of $\beta$ - in either direction (probably, by one to three months). Taking this into account, the trajectories may be thought of as being in good agreement with one another. Hence, despite the fact that they are harvests of quite different methodologies, both the trajectories provide the similar pattern of integration in the Russian market.

Besides the cost of the food basket, Berkowitz and DeJong (2001) use one more price indicator, namely, a regional consumer price index $(\mathrm{CPI})$. The integration trajectory produced by CPI considerably differs from that based on the basket-cost data, indicating less degree of integration. There are two possible reasons of this. The first is noted by the authors themselves; the case in point is that the general CPI covers services, so distorting dispersion of prices for tradable commodities. The second reason is insufficient reliability of the Russian regional CPIs. As found by Gluschenko (2001b), they are severely biased with respect to spatial price indices, overstating inter-regional differences. That is the reason why absolute price of a good basket is favored over CPI in this paper despite much - about 3 times wider coverage of foodstuffs provided by the latter. 


\section{Anatomy of Market Segmentation}

Having found that the Russian market is not near to be completely integrated, even though distances and difficult access to a number of regions are controlled for, the question now naturally arises of culprits behind this. Berkowitz and DeJong (2001) analyzed the influence of political and macroeconomic environment on integration of Russian regional markets. No less tempting is to reveal immediate causes of market frictions integrally reflected by the integration (or, more precisely, segmentation) measure $\beta$. This implies that the dissection of $\beta I_{r s}$ representing unobservable arbitrage transaction costs should be made, so specifying its internal texture.

As noted in Section 2, if one knew building blocks of barriers to arbitrage, the income dispersion variable would appear as unneeded. Taken jointly, these blocks would substitute it, which manifest itself in reduction of $\beta$ to zero with insertion them to Equation (4). Intuitively, impediments to inter-regional trade in Russia - albeit they are numerous - are rather known; they are widely covered in the literature and in the mass media. Among them are: poor market infrastructure, fragmentary market structure (described by Ericson (2001) unfortunately, too briefly) and related institutional factors, lack of information on arbitrage opportunities, regional protectionism (in particular, administrative barriers to trade, i.e., blocking outside supply and forbidding export by regional authorities), state intervention in economy, organized crime, etc. The trouble is that all of them are difficult to quantify. For this, it succeeded in proxying only a portion of culprits behind market segmentation. These are as follows.

Shipping conditions Besides transportation costs, conditions of shipping goods can impede inter-regional trade, so widening price dispersion. Two variables are adopted to proxy this market friction: the quality of region's transport infrastructure and the regional freight tariff. The former is drawn from Matiyasevich et al. (1998). For this variable to change in the same direction as the price dispersion, their original index is reversed by subtracting it from 1, so that the larger the number, the worse the region's transport infrastructure; the index varies from 0 to 1 . (Hence, it actually is the index of infrastructure imperfection.) The variable for a pair of regions is constructed as the difference of the indices for these regions. Although the data used to calculate the index are dated to 1996, the index is believed to be inertial enough, and is expanded over the entire span of time considered. To construct the regional freight tariff variable, yearly regional freight-tariff indices from Goskomstat (2000) are used. For a given year, the base index is calculated by the chain method, taking 1991 to be 1. Thus, this is the level of within-region freight tariff at the end of a year (related to the level of 1991). The pair wise variable is the logarithm ratio of such base indices in regions of the pair. 
State intervention in economy. Two variables represent it: price regulations and subsidizing. The former is the proportion of goods and services with regulated prices in the region in the first quarter of 1996; the data source is Goskomstat (probably, not published). The latter is production subsidies as a proportion of the regional budget expenditures in 1995 by information of RECEP (the initial source is unknown). The relevant pair wise variable is the logarithm ratio of regional indicators. The same values are used for the entire time span under consideration. It is very probable that these values were changing sufficiently during this period. Beyond the years for which the indicat ors were calculated, they are interpreted as the proxies of propensity to price regulating and subsidizing production in the region.

Organized crime. Two proxies of organized crime are available. The first is the total crime rate, i.e., the number of registered crimes per 10,000 of the population. The source of (yearly) data is Goskomstat (2000). The crime rate variable is the logarithm ratio of indicators for regions of a pair. The second proxy describes economic power of crime as the proportion of the regional economy controlled by criminal groups in 1995/1996 according to Kakotkin (1996). Following Brown and Earle (2000), the relevant regional variable is quantified as equaling 1 if criminal groups control more than $50 \%$ of the economy, 0.75 if they control 35$50 \%, 0.5$ if they control $20-35 \%$, and 0.25 if they control less than $20 \%$. The pair wise variable is constructed as the difference of these values for the regions belonging to the pair. The values are expanded over the entire period. Correlation between these measures of organized crime is weak, 0.095 as a maximum; its sign varies across years and region samples. This suggests that two proxies of organized crime are far from being simply versions of each other. Supposedly, they reflect two different dimensions of organized crime (both being merely a rough approximation of it). The activity of criminal groups in legal business qualitatively differs from that of ordinary gangs; when occurring here, crimes as such are much more latent since they are mainly of economic nature. And so, it does not seem that more economic power of crime in a region would necessarily increase the total number of crimes. That is why both the variables are contemporaneously included into the regressions.

So there are 6 additional variables approximating market frictions. (In fact, more variables were tried, but they appeared to be statistically insignificant in all or most of regressions.) Only two of them are time-varying. For this reason (as well as for very crude approximation) it would hardly be worthwhile to analyze their temporal impacts. Therefore aggregate analysis is implemented, using a (random effects) panel model. However, the direction of changes in effect of organized crime on market integration is of specific interest. To identify it, the organized crime variables, say $X_{r s}$, enter into the panel regressions with trended coefficients, $\left(\mu_{0}+\mu t\right) X_{r s}$, where $t$ is time $\left(t=0\right.$ for $1993, t=1$ for 1994 , etc.), $\mu_{0}$ and $\mu$ are parameters to be estimated. In other words, both $X_{r s}$ and $X_{r s} t$ (referred to as trend or trended value in tables below) are included into the panel regressions. Lacking data on some variables for 1992 and 2000, the panels cover 1993 through 1999 (with yearly frequency). Due to missed observations on additional variables, the cross-sections are shorter in the 
panels, namely, entire Russia includes 2415 region pairs, Russia excluding difficult-to-access regions includes 2145 pairs, and European Russia includes 1128 pairs.

The results of panel analysis are reported in Table 3. Panel Model A means the panel version of cross-sectional Model 2 (see Section 5). Its estimates serve as the benchmark for Panel Model B containing additional variables. "Contribution" columns of the table contain percent contributions of relevant variables to price dispersion. The contributions are calculated in the same manner as those in Table 2. A difference is only in that percents in Table 3 are rounded off to the first decimal place in order to preserve small contributions. It is seen from the above-described construction of the additional variables that the are relative values that do not contribute to the regression intercepts; this becomes quite obvious, if one interprets constructing of pairwise variables similarly to going from Equation (1) to Equation (2). Thus the intercept again owes its origin solely to the scaling multiplier for distance, and so, it should be attributed to the contribution of distance to price dispersion. Extra data used to calculate the contributions of variables are set out in appendix Table A-5.

Table 3. Panel regression results and economic importance of variables

\begin{tabular}{|c|c|c|c|c|c|c|}
\hline \multirow[t]{2}{*}{ Variable } & \multicolumn{2}{|c|}{ Entire Russia } & \multicolumn{2}{|c|}{$\begin{array}{l}\text { Excluding difficult-to- } \\
\text { access regions }\end{array}$} & \multicolumn{2}{|c|}{ European Russia } \\
\hline & Estimate & Contribution & Estimate & Contribution & Estimate & Contribution \\
\hline \multicolumn{7}{|c|}{ Panel Model A } \\
\hline Income & $\begin{array}{l}0.105 \\
(0.003)\end{array}$ & 13.1 & $\begin{array}{l}0.062 \\
(0.003)\end{array}$ & 7.8 & $\begin{array}{l}0.064 \\
(0.004)\end{array}$ & 8.9 \\
\hline Distance & $\begin{array}{l}0.114^{\star * *} \\
(0.003)\end{array}$ & 84.6 & $\begin{array}{l}0.061^{\star \star \star} \\
(0.002)\end{array}$ & 92.2 & $\begin{array}{l}0.010^{* * *} \\
(0.003)\end{array}$ & 91.1 \\
\hline Distribution costs & $\begin{array}{l}0.071^{\star \star \star} \\
(0.008)\end{array}$ & 2.3 & $\begin{array}{c}0.002 \\
(0.008)\end{array}$ & 0.0 & $\begin{array}{c}0.010 \\
(0.014)\end{array}$ & 0.0 \\
\hline \multicolumn{7}{|c|}{ Panel Model B } \\
\hline Income dispersion & $\begin{array}{l}0.082 \\
(0.003)\end{array}$ & 10.2 & $\begin{array}{l}0.048 \\
(0.003)\end{array}$ & 6.1 & $\begin{array}{l}0.044 \\
(0.004)\end{array}$ & 6.2 \\
\hline Distance & $\begin{array}{l}0.106^{* * *} \\
(0.003)\end{array}$ & 77.9 & $\begin{array}{l}0.052^{* * *} \\
(0.002)\end{array}$ & 82.3 & $\begin{array}{c}0.005 \\
(0.003)\end{array}$ & 81.8 \\
\hline Distribution costs & $\begin{array}{l}0.097^{\star \star *} \\
(0.008)\end{array}$ & 3.2 & $\begin{array}{l}0.019^{* *} \\
(0.009)\end{array}$ & 0.5 & $\begin{array}{l}0.015 \\
(0.014)\end{array}$ & -0.1 \\
\hline $\begin{array}{r}\text { Transport } \\
\text { infrastructure }\end{array}$ & $\begin{array}{l}0.043^{\star * \star} \\
(0.007)\end{array}$ & 1.1 & $\begin{array}{l}0.026 \\
(0.006)\end{array}$ & 0.6 & $\begin{array}{l}-0.021^{* * *} \\
(0.008)\end{array}$ & 0.5 \\
\hline Regional freight tariff & $\begin{array}{l}-0.000 \\
(0.001)\end{array}$ & 0.0 & $\begin{array}{l}0.006^{* * *} \\
(0.001)\end{array}$ & 1.1 & $\begin{array}{l}0.002^{*+} \\
(0.001)\end{array}$ & 0.1 \\
\hline Price regulations & $\begin{array}{l}-0.005^{* * *} \\
(0.002)_{* *}\end{array}$ & 0.3 & $\begin{array}{l}-0.000 \\
(0.001)\end{array}$ & 0.0 & $\begin{array}{l}-0.008^{* * *} \\
(0.002)\end{array}$ & 1.0 \\
\hline Subsidizing & $\begin{array}{l}-0.017^{* * *} \\
(0.008)\end{array}$ & 1.1 & $\begin{array}{l}-0.017^{* * *} \\
(0.002)\end{array}$ & 1.5 & $\begin{array}{l}-0.020^{* * *} \\
(0.002)\end{array}$ & 3.1 \\
\hline Crime rate & $\begin{array}{l}0.164^{* * *} \\
(0.004)\end{array}$ & 13.1 & $\begin{array}{l}0.165^{\star \star \star} \\
(0.003)\end{array}$ & 16.9 & $\begin{array}{l}0.146 \\
(0.004)\end{array}$ & 12.1 \\
\hline Its trend & $\begin{array}{l}-0.043^{* * *} \\
(0.001)\end{array}$ & -8.5 & $\begin{array}{l}-0.041^{* * *} \\
(0.001)\end{array}$ & -10.3 & $\begin{array}{l}-0.024^{* * *} \\
(0.001)\end{array}$ & -5.9 \\
\hline $\begin{array}{r}\text { Economic power of } \\
\text { organized crime }\end{array}$ & $\begin{array}{l}0.095^{* *} \\
(0.004)_{* *}\end{array}$ & 4.0 & $\begin{array}{l}0.080^{* * *} \\
(0.004)_{* \star *}\end{array}$ & 3.5 & $\begin{array}{l}0.064^{* *} \\
(0.004)_{* \star}\end{array}$ & 3.6 \\
\hline Its trend & $\begin{array}{l}-0.019^{\text {axk }} \\
(0.001)\end{array}$ & -2.4 & $\begin{array}{l}-0.017^{\text {xax }} \\
(0.001)\end{array}$ & -2.2 & $\begin{array}{l}-0.013^{* \times x} \\
(0.001)\end{array}$ & -2.4 \\
\hline
\end{tabular}

Notes: Standard errors are in parentheses; ${ }^{* * *},{ }^{* *}$, and ${ }^{*}$ denote significance at the $1 \%, 5 \%$, and $10 \%$ levels. A "negative zero" is the result of the three-digit round-up of a negative estimate. 
The inclusion of variables representing specific market frictions does lead to decrease of $\beta$. However, $\beta$ still remains statistically significant. The decrease equals about $30 \%$ for European Russia, and about $20 \%$ for two other region samples. This would be expected, as the list of the present market frictions is far from complete.

The economic significance of distance grows smaller, too, by $810 \%$. (Interestingly, being estimated over the 7-year panels, the shares of distance are close to each other across region samples regardless of whether specific market frictions are taken into account or are not.) At the same time, the contribution of other two variables associated with transportation costs - transport infrastructure and freight tariff - does not compensate this decrease. This suggests that there are other variables correlated - truly or spuriously - with distance. In general, the contribution of the additional transport-related variables to price dispersion is little (if any), ranging from $0.6 \%$ to $1.7 \%$. The coefficient on transport infrastructure has the abnormal negative sign in European Russia. It is the Moscow market that causes this phenomenon. When Moscow is excluded from the European Russia sample, the coefficient becomes positive, equaling 0.049 with the statistical significance at the $0.1 \%$ level. (In doing so, distance turns out to be significant, $\gamma=0.010$, and freight tariff appears to be insignificant.) The point is that transport infrastructure is "perfect" in Moscow (it is the only region where the transport infrastructure variable has the zero value), while prices are high, hence the reverse relationship between these variables.

As for distribution costs, their contribution to price dispersion, while estimated over panels, is minor, if any. Though, the effect of distribution costs becomes more distinct if there are variables for specific market frictions in the regressions.

Turning to state intervention in economy, the most interesting feature is the negative sign of estimates of both relevant variables across all region samples. The matter is that prices and, say, the extent of price regulations change in opposite directions: the stronger the regulations, the lower prices. On the other hand, the same forces the means of these two variables to have opposite signs. As the result, the contributions of price regulations and subsidizing to price dispersion turn out to be positive. The total contribution of state intervention in economy is about $4 \%$ in European Russia and about $1.5 \%$ in other two region samples.

Organized crime is found to be marked market friction. Its contribution to price dispersion is $6.2 \%(13.1-8.5+4.0-2.4)$ in entire Russia, $7.9 \%$ in Russia without difficult-to-access regions, and $7.4 \%$ in European Russia. This is much more than the contribution of any other identified market friction (of course, except distance). The panel regressions run without trending the organized crime variables yield lesser estimates (significant at the $0.1 \%$ level): 
Crime rate
Economic power of organized crime
Total contribution to price dispersion, \%

Entire Russia
0.036
0.038
4.3

European Russia

0.027

0.026

3.7

The static way of dealing with the organized crime variables sufficiently reduces values of their contributions to price dispersion (by half for European Russia and by a factor of 1.4 for the remaining samples). Nevertheless, the contributions still exceed those of other variables.

The both organized crime variables have statistically significant and negative trends across all region samples, so suggesting that the impact of organized crime on integration is diminishing with time. To check this, yearly cross-sectional regressions were run for 1993 to 1999. Their results corroborate the phenomenon, evidencing that the impact of organized crime was strengthening during the early years of the transition, and then it was permanently weakening; peaks were in 1994 (the crime rate variable) and 1995 (the crime's economic power variable).

Such a finding seems to be rather surprising. However, analyzing the data of a number of sociological surveys, Radayev (1998) finds the same feature in the evolution of crime in Russia. He suggests the following reasons for narrowing the "realm of organized force": the ending of the era of "fast money", the division of spheres of influence, strengthening care (of crime and business which uses its "services") for own security, the shift of crime to "white" and "gray" market segments. ${ }^{8}$ This does not mean that organized crime steps back; it just transforms itself, that is, the opposition of crime and business is changing to interosculation.

About $80 \%$ of price dispersion is due to the impact of physical distance. It would be conveniently to evaluate the economic importance of market frictions also as their contribution to the remaining part of price dispersion. Unidentified market frictions, the impact of which is represented by $\beta$, account for $46 \%$ of it in entire Russia; $28 \%$ are due to organized crime (19\% according to the regression without trend); distribution costs contribute $14 \%$; and $6 \%$ is provided by state intervention in economy. For Russia excluding difficult-toaccess-regions, the unidentified frictions are responsible for $34 \%$ of price dispersion; $45 \%$ (or $33 \%$, omitting trends) is due to organized crime; shipping conditions add $9 \%$; and state intervention accounts for $8 \%$. At last, in European Russia, the share of unidentified forces is, again, $34 \%$; organized crime contributes $41 \%$ (or $22 \%$, if there are no trends); and $22 \%$ are due to price regulations and subsidies. Appendix Figure A-8 illustrates economic significance of various market frictions measured relative to both total price dispersion and that less the contribution of distance.

\footnotetext{
8 "The time when risky money, big and fast, was made is over. Nowadays this is a routine, a complex and hard job; no superprofit is here, and where it lacks, extortioners do not intrude there", - cites Radayev (1998), p. 60, his respondent.
} 


\section{Conclusions}

Using data across 74 Russian regions from the very beginning of the price liberalization to the recent years, changes in the degree of market integration in Russia during this period are evaluated. The pattern obtained is consistent with results by Berkowitz and DeJong (2001) who use a quite different methodology. This pattern is rather encouraging. After a period of growing disconnectedness, integration of the Russian market tends to improve, though with some deviations from this general trend.

As the dependence of regional prices on local demand still persists, the Russian market cannot be deemed as being completely integrated even by now. However, the question of how far it is from complete integration remains open. The quantitative results suggest that the 1-percent change in local per capita incomes induced 0.05 to 0.1 -percent change in price dispersion in 2000. But is this much or little? On the other hand, the issue of what degree of market integration is really achievable is vague as well. Having no other reference point, one is forced to base judgments on the theoretical standard suggesting comparison with the zero value of $\beta$. But such a comparison may be too severe for the Russian market, overstating its shortcomings.

The point is that there is some evidence that actual economies thought of as being integrated do not match this speculative standard as well, in other words, that they are not completely integrated. For example, Morgan (1998) estimates the food price dispersion across the Euro-zone countries as ranging up to 1.43. Moreover, this pertains equally to the US economy. The ACCRA cost-of-living index for the forth quarter 1999 (drawn from www.infoplease.com/ipa/A0855786.html) indicates that the cost of groceries varies 1.4-fold across US cities, from 0.9 of the national average in San Antonio, Texas, to 1.26 in San Diego, California. There is a portion of results by Engel and Rogers (1996) that can be interpreted as an indication of the fact that price dispersion across US cities depends on local demand like in Russia (Gluschenko, 2002a, discusses this in more detail).

Hence, to evenly judge to what extent the Russian market is integrated, deviations of $\beta$ from a really achievable value - i.e., peculiar to advanced market economies - should be considered rather than deviations from the theoretical standard. Besides that, it is unknown whether relatively small fluctuations of the degree of integration (such as in 1999-2000) are a feature of the Russian market or they are merely random shocks. And so, it would be very helpful to apply the methodology put forward here to an advanced market economy. This would provide the realistic benchmark to judge how far the behavior of the Russian economy deviates from that of actual market economies. 


\section{References}

Berkowitz, D., D. DeJong and S. Husted (1998), 'Quantifying Russia's Price Liberalization', Journal of Comparative Economics, 26, pp. 735-760.

Berkowitz, D. and D. DeJong (1999), 'Russia's Internal Border', Regional Science and Urban Economics, 29, pp. 633-649.

Berkowitz, D. and D. DeJong (2001), 'The Evolution of Market Integration in Russia', Economics of Transition, 9(1), pp. 87-104.

Brown, D. and J. Earle (2000), 'Competition, Geography, and Firm Performance: Lessons from Russia'. Paper presented at CEPR/WDI Annual International Conference on Transition Economics, Moscow, 2/5 July.

De Masi, P. and V. Koen (1996), 'Relative Price Convergence in Russia', IMF Staff Papers, 43, pp. 97-122.

Engel, Ch. and J. Rogers (1996), 'How Wide Is the Border?', American Economic Review, 86(5), pp. 1112-1125.

Ericson, R. (2001), 'Does Russia Have a "Market Economy"', East European Politics and Societies, 15(2), pp. 291-319.

Frenkel', A. (1997), The Russian Economy in 1992-1997: Trends, Analysis, Forecast', Moscow: Finstatinform.

Gardner, B. and K. Brooks (1994), 'Food Prices and Market Integration in Russia: 1992-93', American Journal of Agricultural Economics, 76, pp. 641-666.

Gluschenko, K. (2001a), 'Inter-regional variability of Inflation Rates', EERC Working Paper No. 99/17, Moscow, www.eerc.ru/Publications/workpapers/WP_99-17E.pdf.

Gluschenko, K. (2001b), 'Consumer Prices in Russia in 1992-2000: Spatial Dmension', Region: Ekonomika i Sotsiologia, No. 2, pp. 46-71.

Gluschenko, K. (2002a), 'Common Russian Market: Myth rather than Reality', EERC Working Paper No. 01/11, Moscow, www.eerc.ru/Publications/workpapers/WP_0111E.pdf. 
Gluschenko, K. (2002b), 'Econometric Analysis of Russia's Internal Market Integration', Region: Ekonomika i Sotsiologia, No. 3.

Goodwin, B., T. Grennes and C. McCurdy (1999), 'Spatial Price Dynamics and Integration in Russian Food Markets', Journal of Policy Reform, 3(2), pp. 157-193.

Goskomstat of Russia (1996a), 'Methodological Regulations on Statistics', Issue 1, Moscow.

Goskomstat of Russia (1996b), 'Trade in Russia', Moscow.

Goskomstat of Russia (1998), 'Trade in Russia', Moscow.

Goskomstat of Russia (2000), 'Regions of Russia', Moscow.

Kakotkin, A. (1996), 'The Triumph of Crime', Argumenty i Fakty, No. 30, p. 8.

Koen, V. and P. de Masi (1997), 'Prices in the Transition: Ten Stylized Facts', IMF Working Paper No. 97/158, www.imf.org/external/pubs/ft/wp/wp97158.pdf.

Koen, V. and S Phillips (1992), 'Price Liberalization in Russia: The Early Record', IMF Working Paper No. 92/92.

Matiyasevich T., N. Mögel, S. A. Nagaev, M. Rossmann, L. I. Smirnych, A. Wörgötter (1998), 'Russia: Regional Risk Rating', Vienna: Bank Austria AG.

Morgan, J. P. (1998), 'Welcome to the EMU', European Economic Outlook (Special Edition, October/November), London, Oct. 30.

Obstfeld, M. and A. M. Taylor (1997), 'Non-Linear Aspects of Good-Market Arbitrage and Adjustment: Heckscher's Commodity Points Revisited', Journal of Japanese and International Economies, 11, pp. 441-479.

Parsley, D. and Sh.-J. Wei (1996), 'Convergence to the Law of One Price without Trade Barriers or Currency Fluctuations', Quarterly Journal of Economics, 111, pp. 1211-1236.

Radayev, V. (1998), 'On the Role of Force in Russian Business Relationships', Voprosy Ekonomiki, No. 10, pp. 81-100.

Serova, E. (2000), 'Russia', in Valdes, A. (ed.), 'Agricultural Support Policies in Transition Economies', Washington, DC: World Bank. 


\section{Appendix}

Table A-1. Composition and Structure of the Basket of 25 Basic Food Goods

\begin{tabular}{|c|c|c|c|}
\hline No. & Good & $\begin{array}{l}\text { Unit of } \\
\text { measure }\end{array}$ & Quantity \\
\hline 1 & Rye-and-wheat bread & $\mathrm{kg}$ & 68.7 \\
\hline 2 & White bread & $\mathrm{kg}$ & 62.9 \\
\hline 3 & Flour & $\mathrm{kg}$ & 19.5 \\
\hline 4 & Rice & $\mathrm{kg}$ & 3.7 \\
\hline 5 & Millet & $\mathrm{kg}$ & 9.8 \\
\hline 6 & Vermicelli & $\mathrm{kg}$ & 5.2 \\
\hline 7 & Potatoes & $\mathrm{kg}$ & 124.2 \\
\hline 8 & Cabbages & $\mathrm{kg}$ & 28.1 \\
\hline 9 & Carrots & $\mathrm{kg}$ & 37.5 \\
\hline 10 & Onions & $\mathrm{kg}$ & 28.4 \\
\hline 11 & Apples & $\mathrm{kg}$ & 19.4 \\
\hline 12 & Sugar & $\mathrm{kg}$ & 20.7 \\
\hline 13 & Beef & $\mathrm{kg}$ & 8.4 \\
\hline 14 & Poultry-meat & $\mathrm{kg}$ & 17.5 \\
\hline 15 & Boiled sausage & $\mathrm{kg}$ & 0.45 \\
\hline 16 & $\begin{array}{l}\text { Boiled-and-smoked } \\
\text { sausage }\end{array}$ & $\mathrm{kg}$ & 0.35 \\
\hline 17 & Frozen fish & $\mathrm{kg}$ & 11.7 \\
\hline 18 & Milk & 1 & 123.1 \\
\hline 19 & Sour cream & $\mathrm{kg}$ & 1.6 \\
\hline 20 & Butter & $\mathrm{kg}$ & 2.5 \\
\hline 21 & Curd & $\mathrm{kg}$ & 9.9 \\
\hline 22 & Cheese & $\mathrm{kg}$ & 2.3 \\
\hline 23 & Eggs & piece & 151.4 \\
\hline 24 & Margarine & $\mathrm{kg}$ & 3.9 \\
\hline 25 & Vegetable oil & $\mathrm{kg}$ & 6.4 \\
\hline
\end{tabular}

Source: Goskomstat (1996a), p. 428. 
Table A-2. Estimation Results

\begin{tabular}{|c|c|c|c|c|c|c|c|c|c|c|c|c|}
\hline \multirow[t]{2}{*}{ Period } & \multicolumn{4}{|c|}{ Entire Russia } & \multicolumn{4}{|c|}{ Excluding difficult-to-access regions } & \multicolumn{4}{|c|}{ European Russia } \\
\hline & (s.e.) & p-value & (s.e.) & $\mathrm{p}$-value & (s.e.) & $p$-value & (s.e.) & $p$-value & (s.e.) & p-value & (s.e.) & p-value \\
\hline 1992:02 & $0.019(0.006)$ & 0.004 & $0.010(0.003)$ & 0.002 & $0.010(0.008)$ & 0.223 & $0.006(0.004)$ & 0.070 & $-0.019(0.014)$ & 0.171 & $0.020(0.006)$ & 0.002 \\
\hline 1992:03 & $0.094(0.009)$ & 0.000 & $0.026(0.004)$ & 0.000 & $0.057(0.009)$ & 0.000 & $0.001(0.004)$ & 0.889 & $0.020(0.015)$ & 0.191 & $0.012(0.007)$ & 0.082 \\
\hline 1992:04 & $0.111(0.008)$ & 0.000 & $0.023(0.004)$ & 0.000 & $0.070(0.008)$ & 0.000 & $0.013(0.004)$ & 0.002 & $0.060(0.013)$ & 0.000 & $0.003(0.007)$ & 0.701 \\
\hline 1992:05 & $0.112(0.007)$ & 0.000 & $0.025(0.003)$ & 0.000 & $0.074(0.008)$ & 0.000 & $0.016(0.004)$ & 0.000 & $0.063(0.011)$ & 0.000 & $-0.001(0.006)$ & 0.838 \\
\hline 1992:06 & $0.100(0.006)$ & 0.000 & $0.032(0.003)$ & 0.000 & $0.070(0.007)$ & 0.000 & $0.011(0.003)$ & 0.001 & $0.067(0.013)$ & 0.000 & $0.013(0.006)$ & 0.027 \\
\hline 1992:07 & $0.099(0.005)$ & 0.000 & $0.008(0.003)$ & 0.006 & $0.060(0.005)$ & 0.000 & $-0.005(0.003)$ & 0.128 & $0.041(0.010)$ & 0.000 & $0.021(0.006)$ & 0.000 \\
\hline 1992:08 & $0.150(0.009)$ & 0.000 & $0.043(0.004)$ & 0.000 & $0.066(0.008)$ & 0.000 & $0.018(0.004)$ & 0.000 & $0.041(0.013)$ & 0.001 & $0.022(0.006)$ & 0.000 \\
\hline 1992:09 & $0.183(0.010)$ & 0.000 & $0.065(0.005)$ & 0.000 & $0.085(0.012)$ & 0.000 & $0.037(0.005)$ & 0.000 & $-0.061(0.019)$ & 0.002 & $0.020(0.007)$ & 0.004 \\
\hline $1992: 10$ & $0.201(0.009)$ & 0.000 & $0.052(0.004)$ & 0.000 & $0.112(0.009)$ & 0.000 & $0.021(0.004)$ & 0.000 & $0.026(0.014)$ & 0.066 & $0.015(0.007)$ & 0.022 \\
\hline 1992:11 & $0.171(0.009)$ & 0.000 & $0.036(0.004)$ & 0.000 & $0.110(0.009)$ & 0.000 & $0.013(0.004)$ & 0.003 & $0.068(0.016)$ & 0.000 & $0.017(0.007)$ & 0.012 \\
\hline 1992:12 & $0.186(0.010)$ & 0.000 & $0.036(0.004)$ & 0.000 & $0.132(0.011)$ & 0.000 & $0.013(0.005)$ & 0.005 & $0.120(0.018)$ & 0.000 & $0.014(0.008)$ & 0.073 \\
\hline 1993:01 & $0.077(0.009)$ & 0.000 & $0.052(0.005)$ & 0.000 & $0.038(0.010)$ & 0.000 & $0.038(0.005)$ & 0.000 & $-0.034(0.017)$ & 0.041 & 0.007 (0.008) & 0.372 \\
\hline 1993:02 & $0.111(0.009)$ & 0.000 & $0.044(0.005)$ & 0.000 & $0.049(0.010)$ & 0.000 & $0.025(0.005)$ & 0.000 & $0.024(0.017)$ & 0.161 & $0.002(0.009)$ & 0.797 \\
\hline 1993:03 & $0.084(0.009)$ & 0.000 & $0.026(0.005)$ & 0.000 & $0.022(0.010)$ & 0.029 & $0.011(0.005)$ & 0.050 & $-0.064(0.019)$ & 0.001 & $0.019(0.010)$ & 0.053 \\
\hline 1993:04 & $0.148(0.009)$ & 0.000 & $0.037(0.004)$ & 0.000 & $0.077(0.010)$ & 0.000 & $0.021(0.004)$ & 0.000 & $0.065(0.017)$ & 0.000 & $0.014(0.007)$ & 0.050 \\
\hline 1993:05 & $0.127(0.008)$ & 0.000 & $0.049(0.004)$ & 0.000 & $0.054(0.008)$ & 0.000 & $0.029(0.004)$ & 0.000 & $0.022(0.015)$ & 0.153 & $0.022(0.007)$ & 0.001 \\
\hline 1993:06 & $0.219(0.010)$ & 0.000 & $0.065(0.004)$ & 0.000 & $0.103(0.008)$ & 0.000 & $0.036(0.004)$ & 0.000 & $0.106(0.015)$ & 0.000 & $0.014(0.007)$ & 0.027 \\
\hline 1993:07 & $0.224(0.011)$ & 0.000 & $0.078(0.005)$ & 0.000 & $0.087(0.011)$ & 0.000 & $0.040(0.005)$ & 0.000 & $0.103(0.019)$ & 0.000 & $0.008(0.008)$ & 0.316 \\
\hline 1993:08 & $0.316(0.011)$ & 0.000 & $0.102(0.004)$ & 0.000 & $0.166(0.010)$ & 0.000 & $0.068(0.004)$ & 0.000 & $0.157(0.014)$ & 0.000 & $0.015(0.005)$ & 0.005 \\
\hline 1993:09 & $0.256(0.010)$ & 0.000 & $0.096(0.004)$ & 0.000 & $0.124(0.009)$ & 0.000 & $0.064(0.004)$ & 0.000 & $0.083(0.011)$ & 0.000 & $0.010(0.005)$ & 0.068 \\
\hline 1993:10 & $0.294(0.012)$ & 0.000 & $0.114(0.004)$ & 0.000 & $0.146(0.010)$ & 0.000 & $0.077(0.004)$ & 0.000 & $0.092(0.013)$ & 0.000 & $0.008(0.005)$ & 0.135 \\
\hline 1993:11 & $0.302(0.011)$ & 0.000 & $0.116(0.004)$ & 0.000 & $0.176(0.010)$ & 0.000 & $0.077(0.004)$ & 0.000 & $0.108(0.014)$ & 0.000 & $0.017(0.005)$ & 0.002 \\
\hline 1993:12 & $0.208(0.011)$ & 0.000 & $0.107(0.004)$ & 0.000 & $0.106(0.010)$ & 0.000 & $0.078(0.004)$ & 0.000 & $0.062(0.015)$ & 0.000 & $0.027(0.006)$ & 0.000 \\
\hline 1994:01 & $0.178(0.009)$ & 0.000 & $0.119(0.004)$ & 0.000 & $0.092(0.008)$ & 0.000 & $0.085(0.004)$ & 0.000 & $0.067(0.012)$ & 0.000 & $0.022(0.006)$ & 0.001 \\
\hline 1994:02 & $0.223(0.009)$ & 0.000 & $0.101(0.004)$ & 0.000 & $0.120(0.009)$ & 0.000 & $0.075(0.004)$ & 0.000 & $0.132(0.013)$ & 0.000 & $0.019(0.006)$ & 0.001 \\
\hline 1994:03 & $0.217(0.010)$ & 0.000 & $0.102(0.004)$ & 0.000 & $0.108(0.008)$ & 0.000 & $0.068(0.004)$ & 0.000 & $0.089(0.011)$ & 0.000 & $0.017(0.005)$ & 0.001 \\
\hline 1994:04 & $0.251(0.011)$ & 0.000 & $0.135(0.005)$ & 0.000 & $0.103(0.008)$ & 0.000 & $0.076(0.004)$ & 0.000 & $0.098(0.012)$ & 0.000 & $0.006(0.006)$ & 0.288 \\
\hline 1994:05 & $0.229(0.010)$ & 0.000 & $0.113(0.004)$ & 0.000 & $0.077(0.006)$ & 0.000 & $0.063(0.004)$ & 0.000 & $0.097(0.009)$ & 0.000 & $0.032(0.005)$ & 0.000 \\
\hline 1994:06 & $0.232(0.010)$ & 0.000 & $0.106(0.004)$ & 0.000 & $0.075(0.005)$ & 0.000 & $0.046(0.003)$ & 0.000 & $0.069(0.007)$ & 0.000 & $-0.003(0.004)$ & 0.531 \\
\hline 1994:07 & $0.229(0.009)$ & 0.000 & $0.112(0.005)$ & 0.000 & $0.102(0.007)$ & 0.000 & $0.060(0.004)$ & 0.000 & $0.100(0.009)$ & 0.000 & $0.052(0.006)$ & 0.000 \\
\hline 1994:08 & $0.313(0.010)$ & 0.000 & $0.135(0.004)$ & 0.000 & $0.147(0.008)$ & 0.000 & $0.087(0.004)$ & 0.000 & $0.151(0.009)$ & 0.000 & $0.031(0.005)$ & 0.000 \\
\hline 1994:09 & $0.296(0.009)$ & 0.000 & $0.145(0.004)$ & 0.000 & 0.159 & 0.000 & $0.097(0.003)$ & 0.000 & $0.143(0.007)$ & 0.000 & $0.025(0.004)$ & 0.000 \\
\hline 1994:10 & $0.282(0.009)$ & 0.000 & $0.139(0.004)$ & 0.000 & $0.147(0.007)$ & 0.000 & $0.088(0.004)$ & 0.000 & $0.141(0.008)$ & 0.000 & $0.026(0.004)$ & 0.000 \\
\hline 1994:11 & $0.285(0.009)$ & 0.000 & $0.121(0.004)$ & 0.000 & $0.149(0.007)$ & 0.000 & $0.071(0.004)$ & 0.000 & $0.143(0.009)$ & 0.000 & $0.028(0.005)$ & 0.000 \\
\hline $1994: 12$ & $0.252(0.008)$ & 0.000 & $0.099(0.004)$ & 0.000 & $0.148(0.007)$ & 0.000 & $0.060(0.004)$ & 0.000 & $0.150(0.009)$ & 0.000 & $0.028(0.005)$ & 0.000 \\
\hline 1995:01 & $0.171(0.007)$ & 0.000 & $0.096(0.004)$ & 0.000 & $0.101(0.006)$ & 0.000 & $0.056(0.004)$ & 0.000 & $0.095(0.008)$ & 0.000 & $0.037(0.005)$ & 0.000 \\
\hline
\end{tabular}


Cont. Table A-2. Estimation Results

\begin{tabular}{|c|c|c|c|c|c|c|c|c|c|c|c|c|}
\hline \multirow[t]{2}{*}{ Period } & \multicolumn{4}{|c|}{ Entire Russia } & \multicolumn{4}{|c|}{ Excluding difficult-to-access regions } & \multicolumn{4}{|c|}{ European Russia } \\
\hline & (s.e.) & p-value & (s.e.) & p-value & (s.e.) & $p$-value & (s.e.) & p-value & (s.e.) & $p$-value & (s.e.) & $p$-value \\
\hline 1995:02 & $0.176(0.007)$ & 0.000 & $0.111(0.004)$ & 0.000 & $0.113(0.007)$ & 0.000 & $0.076(0.004)$ & 0.000 & $0.104(0.009)$ & 0.000 & $0.029(0.005)$ & 0.000 \\
\hline 1995:03 & $0.171(0.006)$ & 0.000 & $0.118(0.003)$ & 0.000 & $0.117(0.005)$ & 0.000 & $0.081(0.003)$ & 0.000 & $0.118(0.006)$ & 0.000 & $0.016(0.004)$ & 0.000 \\
\hline 1995:04 & $0.180(0.006)$ & 0.000 & $0.112(0.003)$ & 0.000 & $0.124(0.005)$ & 0.000 & $0.078(0.003)$ & 0.000 & $0.120(0.006)$ & 0.000 & $0.014(0.004)$ & 0.000 \\
\hline 1995:05 & $0.166(0.006)$ & 0.000 & $0.101(0.003)$ & 0.000 & $0.109(0.006)$ & 0.000 & $0.066(0.003)$ & 0.000 & $0.105(0.008)$ & 0.000 & $0.017(0.005)$ & 0.000 \\
\hline 1995:06 & $0.173(0.006)$ & 0.000 & $0.086(0.003)$ & 0.000 & $0.112(0.006)$ & 0.000 & $0.051(0.003)$ & 0.000 & $0.092(0.008)$ & 0.000 & $0.009(0.004)$ & 0.027 \\
\hline 1995:07 & $0.209(0.007)$ & 0.000 & $0.102(0.003)$ & 0.000 & $0.145(0.006)$ & 0.000 & $0.075(0.003)$ & 0.000 & $0.158(0.007)$ & 0.000 & $0.018(0.004)$ & 0.000 \\
\hline 1995:08 & $0.231(0.008)$ & 0.000 & $0.119(0.003)$ & 0.000 & $0.139(0.006)$ & 0.000 & $0.083(0.003)$ & 0.000 & $0.156(0.007)$ & 0.000 & $0.012(0.004)$ & 0.002 \\
\hline 1995:09 & $0.222(0.008)$ & 0.000 & $0.119(0.003)$ & 0.000 & $0.130(0.006)$ & 0.000 & $0.084(0.003)$ & 0.000 & $0.147(0.007)$ & 0.000 & $0.013(0.004)$ & 0.000 \\
\hline 1995:10 & $0.210(0.008)$ & 0.000 & $0.114(0.003)$ & 0.000 & $0.114(0.006)$ & 0.000 & $0.073(0.003)$ & 0.000 & $0.130(0.008)$ & 0.000 & $0.011(0.004)$ & 0.005 \\
\hline 1995:11 & $0.201(0.008)$ & 0.000 & $0.114(0.003)$ & 0.000 & $0.108(0.006)$ & 0.000 & $0.066(0.003)$ & 0.000 & $0.125(0.007)$ & 0.000 & $0.006(0.004)$ & 0.134 \\
\hline 1995:12 & $0.161(0.007)$ & 0.000 & $0.115(0.003)$ & 0.000 & $0.084(0.006)$ & 0.000 & $0.067(0.003)$ & 0.000 & $0.096(0.006)$ & 0.000 & $0.007(0.004)$ & 0.078 \\
\hline 1996:01 & $0.134(0.007)$ & 0.000 & $0.134(0.004)$ & 0.000 & $0.053(0.006)$ & 0.000 & $0.077(0.003)$ & 0.000 & $0.071(0.007)$ & 0.000 & $0.012(0.004)$ & 0.005 \\
\hline 1996:02 & $0.135(0.007)$ & 0.000 & $0.132(0.004)$ & 0.000 & $0.058(0.006)$ & 0.000 & $0.078(0.003)$ & 0.000 & $0.077(0.006)$ & 0.000 & $0.013(0.004)$ & 0.001 \\
\hline 1996:03 & $0.165(0.008)$ & 0.000 & $0.132(0.004)$ & 0.000 & $0.082(0.006)$ & 0.000 & $0.081(0.003)$ & 0.000 & $0.089(0.006)$ & 0.000 & $0.006(0.004)$ & 0.078 \\
\hline 1996:04 & $0.166(0.008)$ & 0.000 & $0.133(0.004)$ & 0.000 & $0.073(0.006)$ & 0.000 & $0.074(0.003)$ & 0.000 & $0.093(0.006)$ & 0.000 & $0.009(0.003)$ & 0.008 \\
\hline 1996:05 & $0.127(0.008)$ & 0.000 & $0.134(0.004)$ & 0.000 & $0.045(0.005)$ & 0.000 & $0.076(0.003)$ & 0.000 & $0.068(0.005)$ & 0.000 & $0.010(0.003)$ & 0.004 \\
\hline 1996:06 & $0.181(0.009)$ & 0.000 & $0.130(0.004)$ & 0.000 & $0.076(0.006)$ & 0.000 & $0.077(0.003)$ & 0.000 & $0.102(0.006)$ & 0.000 & $0.006(0.003)$ & 0.089 \\
\hline 1996:07 & $0.165(0.008)$ & 0.000 & $0.135(0.004)$ & 0.000 & $0.067(0.006)$ & 0.000 & $0.078(0.003)$ & 0.000 & $0.113(0.006)$ & 0.000 & $0.015(0.003)$ & 0.000 \\
\hline 1996:08 & $0.178(0.007)$ & 0.000 & $0.126(0.003)$ & 0.000 & $0.074(0.005)$ & 0.000 & $0.075(0.003)$ & 0.000 & $0.095(0.005)$ & 0.000 & $0.015(0.003)$ & 0.000 \\
\hline 1996:09 & $0.153(0.007)$ & 0.000 & $0.126(0.003)$ & 0.000 & $0.066(0.005)$ & 0.000 & $0.057(0.003)$ & 0.000 & $0.079(0.005)$ & 0.000 & $0.013(0.003)$ & 0.000 \\
\hline 1996:10 & $0.146(0.007)$ & 0.000 & $0.128(0.003)$ & 0.000 & $0.067(0.005)$ & 0.000 & $0.071(0.003)$ & 0.000 & $0.082(0.005)$ & 0.000 & $0.008(0.003)$ & 0.016 \\
\hline 1996:11 & $0.153(0.007)$ & 0.000 & $0.136(0.003)$ & 0.000 & $0.066(0.005)$ & 0.000 & $0.081(0.003)$ & 0.000 & $0.091(0.005)$ & 0.000 & $0.008(0.003)$ & 0.011 \\
\hline 1996:12 & $0.100(0.007)$ & 0.000 & $0.128(0.004)$ & 0.000 & $0.069(0.005)$ & 0.000 & $0.086(0.003)$ & 0.000 & $0.091(0.005)$ & 0.000 & $0.004(0.003)$ & 0.140 \\
\hline 1997:01 & $0.120(0.006)$ & 0.000 & $0.142(0.004)$ & 0.000 & $0.054(0.004)$ & 0.000 & $0.084(0.003)$ & 0.000 & $0.061(0.004)$ & 0.000 & $0.007(0.002)$ & 0.004 \\
\hline 1997:02 & $0.111(0.007)$ & 0.000 & $0.142(0.004)$ & 0.000 & $0.052(0.004)$ & 0.000 & $0.082(0.003)$ & 0.000 & $0.055(0.004)$ & 0.000 & $0.009(0.002)$ & 0.001 \\
\hline 1997:03 & $0.126(0.007)$ & 0.000 & $0.141(0.004)$ & 0.000 & $0.058(0.004)$ & 0.000 & $0.084(0.003)$ & 0.000 & $0.066(0.004)$ & 0.000 & $0.007(0.002)$ & 0.008 \\
\hline 1997:04 & $0.118(0.007)$ & 0.000 & $0.151(0.004)$ & 0.000 & $0.054(0.005)$ & 0.000 & $0.096(0.003)$ & 0.000 & $0.069(0.004)$ & 0.000 & $0.008(0.002)$ & 0.002 \\
\hline $1997: 05$ & $0.119(0.007)$ & 0.000 & $0.139(0.004)$ & 0.000 & $0.047(0.005)$ & 0.000 & $0.076(0.003)$ & 0.000 & $0.065(0.004)$ & 0.000 & $0.006(0.002)$ & 0.021 \\
\hline 1997:06 & $0.134(0.007)$ & 0.000 & $0.133(0.004)$ & 0.000 & $0.056(0.005)$ & 0.000 & $0.070(0.003)$ & 0.000 & $0.069(0.005)$ & 0.000 & $0.007(0.003)$ & 0.009 \\
\hline 1997:07 & $0.125(0.007)$ & 0.000 & $0.140(0.004)$ & 0.000 & $0.057(0.005)$ & 0.000 & $0.083(0.003)$ & 0.000 & $0.078(0.004)$ & 0.000 & $-0.002(0.003)$ & 0.422 \\
\hline 1997:08 & $0.183(0.007)$ & 0.000 & $0.132(0.003)$ & 0.000 & $0.089(0.005)$ & 0.000 & $0.075(0.003)$ & 0.000 & $0.117(0.004)$ & 0.000 & $0.006(0.002)$ & 0.009 \\
\hline 1997:09 & $0.158(0.007)$ & 0.000 & $0.128(0.003)$ & 0.000 & $0.075(0.005)$ & 0.000 & $0.068(0.003)$ & 0.000 & $0.093(0.005)$ & 0.000 & $0.010(0.002)$ & 0.000 \\
\hline 1997:10 & $0.165(0.007)$ & 0.000 & $0.123(0.003)$ & 0.000 & $0.074(0.005)$ & 0.000 & $0.067(0.003)$ & 0.000 & $0.090(0.006)$ & 0.000 & $0.013(0.003)$ & 0.000 \\
\hline 1997:11 & $0.151(0.007)$ & 0.000 & $0.131(0.003)$ & 0.000 & $0.057(0.005)$ & 0.000 & $0.072(0.003)$ & 0.000 & $0.089(0.005)$ & 0.000 & $0.011(0.003)$ & 0.000 \\
\hline 1997:12 & $0.175(0.007)$ & 0.000 & $0.110(0.003)$ & 0.000 & $0.073(0.005)$ & 0.000 & $0.066(0.003)$ & 0.000 & $0.080(0.005)$ & 0.000 & $0.013(0.003)$ & 0.000 \\
\hline 1998:01 & $0.153(0.007)$ & 0.000 & $0.131(0.003)$ & 0.000 & $0.069(0.005)$ & 0.000 & $0.070(0.003)$ & 0.000 & $0.090(0.005)$ & 0.000 & $0.010(0.003)$ & 0.000 \\
\hline
\end{tabular}


Cont. Table A-2. Estimation Results

\begin{tabular}{|c|c|c|c|c|c|c|c|c|c|c|c|c|}
\hline Period & \multicolumn{4}{|c|}{ Entire Russia } & \multicolumn{4}{|c|}{ Excluding difficult-to-access regions } & \multicolumn{4}{|c|}{ European Russia } \\
\hline & (s.e.) & $p$-value & (s.e.) & $\mathrm{p}$-value & (s.e.) & p-value & (s.e.) & $p$-value & (s.e.) & p-value & (s.e.) & $p$-value \\
\hline 1998:02 & $0.131(0.007)$ & 0.000 & $0.124(0.004)$ & 0.000 & $0.054(0.005)$ & 0.000 & $0.058(0.003)$ & 0.000 & $0.072(0.006)$ & 0.000 & $0.012(0.003)$ & 0.000 \\
\hline 1998:03 & $0.134(0.007)$ & 0.000 & $0.119(0.003)$ & 0.000 & $0.055(0.005)$ & 0.000 & $0.057(0.003)$ & 0.000 & $0.084(0.006)$ & 0.000 & $0.008(0.003)$ & 0.003 \\
\hline 1998:04 & $0.138(0.006)$ & 0.000 & $0.125(0.003)$ & 0.000 & $0.060(0.005)$ & 0.000 & $0.063(0.003)$ & 0.000 & $0.096(0.005)$ & 0.000 & $0.010(0.002)$ & 0.000 \\
\hline 1998:05 & $0.137(0.006)$ & 0.000 & $0.122(0.003)$ & 0.000 & $0.065(0.005)$ & 0.000 & $0.062(0.003)$ & 0.000 & $0.091(0.005)$ & 0.000 & $0.013(0.002)$ & 0.000 \\
\hline 1998:06 & $0.143(0.006)$ & 0.000 & $0.112(0.003)$ & 0.000 & $0.068(0.005)$ & 0.000 & $0.052(0.003)$ & 0.000 & $0.092(0.005)$ & 0.000 & $0.014(0.003)$ & 0.000 \\
\hline 1998:07 & $0.154(0.006)$ & 0.000 & $0.103(0.003)$ & 0.000 & $0.077(0.005)$ & 0.000 & $0.039(0.002)$ & 0.000 & $0.106(0.005)$ & 0.000 & $0.007(0.003)$ & 0.020 \\
\hline 1998:08 & $0.156(0.006)$ & 0.000 & $0.096(0.003)$ & 0.000 & $0.087(0.005)$ & 0.000 & $0.029(0.002)$ & 0.000 & $0.111(0.006)$ & 0.000 & $0.009(0.003)$ & 0.003 \\
\hline 1998:09 & $0.151(0.006)$ & 0.000 & $0.090(0.004)$ & 0.000 & $0.100(0.005)$ & 0.000 & $0.029(0.003)$ & 0.000 & $0.128(0.006)$ & 0.000 & $0.027(0.005)$ & 0.000 \\
\hline 1998:10 & $0.148(0.006)$ & 0.000 & $0.096(0.004)$ & 0.000 & $0.075(0.005)$ & 0.000 & $0.031(0.003)$ & 0.000 & $0.098(0.006)$ & 0.000 & $0.018(0.004)$ & 0.000 \\
\hline 1998:11 & $0.140(0.006)$ & 0.000 & $0.092(0.003)$ & 0.000 & $0.074(0.005)$ & 0.000 & $0.039(0.003)$ & 0.000 & $0.099(0.005)$ & 0.000 & $0.006(0.003)$ & 0.083 \\
\hline 1998:12 & $0.126(0.005)$ & 0.000 & $0.069(0.002)$ & 0.000 & $0.072(0.005)$ & 0.000 & $0.039(0.003)$ & 0.000 & $0.095(0.006)$ & 0.000 & $-0.003(0.003)$ & 0.383 \\
\hline 1999:01 & $0.102(0.005)$ & 0.000 & $0.077(0.003)$ & 0.000 & $0.055(0.004)$ & 0.000 & $0.034(0.002)$ & 0.000 & $0.078(0.005)$ & 0.000 & $-0.001(0.003)$ & 0.812 \\
\hline 1999:02 & $0.111(0.005)$ & 0.000 & $0.065(0.003)$ & 0.000 & $0.056(0.004)$ & 0.000 & $0.019(0.002)$ & 0.000 & $0.072(0.005)$ & 0.000 & $-0.006(0.003)$ & 0.049 \\
\hline 1999:03 & $0.122(0.005)$ & 0.000 & $0.062(0.003)$ & 0.000 & $0.061(0.004)$ & 0.000 & $0.017(0.002)$ & 0.000 & $0.090(0.006)$ & 0.000 & $-0.007(0.003)$ & 0.020 \\
\hline 1999:04 & $0.111(0.005)$ & 0.000 & $0.062(0.003)$ & 0.000 & $0.050(0.004)$ & 0.000 & $0.016(0.002)$ & 0.000 & $0.074(0.005)$ & 0.000 & $-0.003(0.003)$ & 0.318 \\
\hline 1999:05 & $0.107(0.004)$ & 0.000 & $0.046(0.003)$ & 0.000 & $0.056(0.004)$ & 0.000 & $0.005(0.002)$ & 0.014 & $0.085(0.005)$ & 0.000 & $0.000(0.003)$ & 0.962 \\
\hline 1999:06 & $0.102(0.004)$ & 0.000 & $0.042(0.002)$ & 0.000 & $0.053(0.003)$ & 0.000 & $0.004(0.002)$ & 0.035 & $0.078(0.005)$ & 0.000 & $-0.003(0.003)$ & 0.371 \\
\hline 1999:07 & $0.102(0.005)$ & 0.000 & $0.057(0.003)$ & 0.000 & $0.053(0.004)$ & 0.000 & $0.016(0.002)$ & 0.000 & $0.096(0.006)$ & 0.000 & $0.007(0.003)$ & 0.046 \\
\hline 1999:08 & $0.132(0.006)$ & 0.000 & $0.073(0.003)$ & 0.000 & $0.064(0.005)$ & 0.000 & $0.018(0.002)$ & 0.000 & $0.101(0.007)$ & 0.000 & $-0.001(0.004)$ & 0.707 \\
\hline 1999:09 & $0.106(0.005)$ & 0.000 & $0.071(0.003)$ & 0.000 & $0.049(0.005)$ & 0.000 & $0.019(0.002)$ & 0.000 & $0.080(0.006)$ & 0.000 & $0.001(0.003)$ & 0.647 \\
\hline 1999:10 & $0.115(0.005)$ & 0.000 & $0.074(0.003)$ & 0.000 & $0.053(0.005)$ & 0.000 & $0.021(0.002)$ & 0.000 & $0.080(0.006)$ & 0.000 & $0.003(0.003)$ & 0.295 \\
\hline 1999:11 & $0.11 \mathrm{C}(0.005)$ & 0.000 & $0.073(0.003)$ & 0.000 & $0.051(0.005)$ & 0.000 & $0.024(0.002)$ & 0.000 & $0.081(0.006)$ & 0.000 & $0.000(0.003)$ & 0.909 \\
\hline 1999:12 & $0.132(0.005)$ & 0.000 & $0.074(0.003)$ & 0.000 & $0.067(0.005)$ & 0.000 & $0.026(0.002)$ & 0.000 & $0.105(0.005)$ & 0.000 & $-0.004(0.003)$ & 0.153 \\
\hline 2000:01 & $0.105(0.005)$ & 0.000 & $0.085(0.003)$ & 0.000 & $0.053(0.005)$ & 0.000 & $0.035(0.003)$ & 0.000 & $0.086(0.006)$ & 0.000 & $0.002(0.003)$ & 0.454 \\
\hline $2000: 02$ & $0.117(0.005)$ & 0.000 & $0.084(0.003)$ & 0.000 & $0.059(0.005)$ & 0.000 & $0.036(0.002)$ & 0.000 & $0.098(0.005)$ & 0.000 & $0.001(0.003)$ & 0.647 \\
\hline $2000: 03$ & $0.111(0.005)$ & 0.000 & $0.085(0.003)$ & 0.000 & $0.054(0.005)$ & 0.000 & $0.035(0.003)$ & 0.000 & $0.096(0.006)$ & 0.000 & $0.001(0.003)$ & 0.771 \\
\hline 2000:04 & $0.117(0.005)$ & 0.000 & $0.086(0.003)$ & 0.000 & $0.061(0.005)$ & 0.000 & $0.034(0.002)$ & 0.000 & $0.107(0.005)$ & 0.000 & $-0.001(0.003)$ & 0.769 \\
\hline 2000:05 & $0.105(0.005)$ & 0.000 & $0.084(0.003)$ & 0.000 & $0.053(0.004)$ & 0.000 & $0.034(0.002)$ & 0.000 & $0.096(0.005)$ & 0.000 & $-0.001(0.003)$ & 0.748 \\
\hline $2000: 06$ & $0.109(0.005)$ & 0.000 & $0.080(0.003)$ & 0.000 & $0.053(0.004)$ & 0.000 & $0.032(0.002)$ & 0.000 & $0.094(0.004)$ & 0.000 & $-0.001(0.002)$ & 0.766 \\
\hline $2000: 07$ & $0.11 \epsilon(0.005)$ & 0.000 & $0.079(0.003)$ & 0.000 & $0.064(0.004)$ & 0.000 & $0.028(0.002)$ & 0.000 & $0.108(0.005)$ & 0.000 & $0.013(0.003)$ & 0.000 \\
\hline $2000: 08$ & $0.113(0.005)$ & 0.000 & $0.091(0.003)$ & 0.000 & $0.061(0.004)$ & 0.000 & $0.035(0.002)$ & 0.000 & $0.106(0.005)$ & 0.000 & 0.008 (0.003) & 0.008 \\
\hline $2000: 09$ & $0.109(0.005)$ & 0.000 & $0.090(0.003)$ & 0.000 & $0.060(0.004)$ & 0.000 & $0.037(0.003)$ & 0.000 & $0.098(0.005)$ & 0.000 & $0.005(0.003)$ & 0.083 \\
\hline $2000: 10$ & $0.11 \subseteq(0.005)$ & 0.000 & $0.091(0.003)$ & 0.000 & $0.064(0.005)$ & 0.000 & $0.040(0.003)$ & 0.000 & $0.103(0.005)$ & 0.000 & $0.004(0.003)$ & 0.105 \\
\hline $2000: 11$ & $0.11 \mathrm{C}(0.005)$ & 0.000 & $0.097(0.003)$ & 0.000 & $0.063(0.004)$ & 0.000 & $0.046(0.003)$ & 0.000 & $0.099(0.004)$ & 0.000 & $0.002(0.003)$ & 0.397 \\
\hline $2000: 12$ & $0.107(0.005)$ & 0.000 & $0.094(0.003)$ & 0.000 & $0.058(0.004)$ & 0.000 & $0.046(0.003)$ & 0.000 & $0.103(0.004)$ & 0.000 & $0.003(0.003)$ & 0.287 \\
\hline
\end{tabular}

Note: The White heteroscedastic-consistent errors are in parentheses. 
Table A-3. Means of variables

\begin{tabular}{|c|c|c|c|c|c|c|c|c|c|}
\hline Year & \multicolumn{4}{|c|}{ Entire Russia } & \multicolumn{3}{c|}{$\begin{array}{c}\text { Excluding difficult-to- } \\
\text { access regions }\end{array}$} & \multicolumn{3}{c|}{ European Russia } \\
\hline & $P$ & $I$ & $\bar{D}$ & $\bar{P}$ & $I$ & $\bar{D}$ & $\bar{P}$ & $I$ & $\bar{D}$ \\
\hline 1992 & 0.207 & 0.227 & NA & 0.179 & 0.150 & NA & 0.170 & 0.068 & NA \\
1993 & 0.253 & 0.264 & 0.050 & 0.203 & 0.171 & 0.026 & 0.168 & 0.077 & -0.002 \\
1994 & 0.274 & 0.326 & 0.073 & 0.200 & 0.233 & 0.040 & 0.147 & 0.172 & -0.002 \\
1995 & 0.239 & 0.320 & 0.054 & 0.185 & 0.246 & 0.026 & 0.130 & 0.188 & -0.011 \\
1996 & 0.225 & 0.277 & 0.081 & 0.162 & 0.201 & 0.051 & 0.104 & 0.152 & 0.004 \\
1997 & 0.204 & 0.263 & 0.086 & 0.143 & 0.195 & 0.056 & 0.082 & 0.161 & -0.006 \\
1998 & 0.191 & 0.281 & 0.078 & 0.132 & 0.214 & 0.047 & 0.102 & 0.186 & -0.012 \\
1999 & 0.150 & 0.261 & 0.069 & 0.106 & 0.187 & 0.036 & 0.094 & 0.177 & -0.008 \\
2000 & 0.157 & 0.265 & 0.075 & 0.110 & 0.200 & 0.043 & 0.088 & 0.203 & -0.006 \\
\hline
\end{tabular}

Table A-4. Estimated intercept $\alpha(t)$ and the mean of distance

\begin{tabular}{|c|c|c|c|c|c|c|}
\hline \multirow{2}{*}{ Year } & \multicolumn{2}{|c|}{ Entire Russia } & \multicolumn{2}{c|}{$\begin{array}{c}\text { Excluding difficult-to- } \\
\text { access regions }\end{array}$} & \multicolumn{2}{c|}{ European Russia } \\
\cline { 2 - 7 } & Model 1 & Model 2 & Model 1 & Model 2 & Model 1 & Model 2 \\
\hline 1992 & -0.070 & & 0.069 & & 0.066 & \\
1993 & -0.393 & -0.300 & -0.189 & -0.169 & 0.094 & 0.100 \\
1994 & -0.760 & -0.664 & -0.413 & -0.379 & -0.047 & -0.045 \\
1995 & -0.676 & -0.462 & -0.397 & -0.340 & 0.014 & 0.013 \\
1996 & -0.822 & -0.611 & -0.431 & -0.375 & 0.035 & 0.042 \\
1997 & -0.874 & -0.607 & -0.465 & -0.374 & 0.012 & 0.015 \\
1998 & -0.669 & -0.451 & -0.231 & -0.192 & 0.035 & 0.038 \\
1999 & -0.384 & -0.253 & -0.043 & -0.027 & 0.116 & 0.115 \\
2000 & -0.552 & -0.424 & -0.182 & -0.164 & 0.071 & 0.071 \\
\hline$L$ & \multicolumn{2}{|c|}{7.721} & \multicolumn{3}{|c|}{7.550} & \multicolumn{2}{c|}{7.027} \\
\hline
\end{tabular}

Table A-5. The 1993-1999 panel means

\begin{tabular}{|r|c|c|c|}
\hline \multicolumn{1}{|c|}{ Variable } & Entire Russia & $\begin{array}{c}\text { Excluding difficult- } \\
\text { to-access regions }\end{array}$ & European Russia \\
\hline Price dispersion & 0.221 & 0.165 & 0.122 \\
Income dispersion & 0.276 & 0.208 & 0.170 \\
Distance & 7.717 & 7.549 & 7.001 \\
Distribution costs & 0.072 & 0.042 & -0.004 \\
Transport infrastructure & 0.056 & 0.039 & -0.028 \\
Regional freight tariff & 0.285 & 0.308 & 0.071 \\
Price regulations & -0.154 & -0.119 & -0.149 \\
Subsidizing & -0.147 & -0.143 & -0.183 \\
Crime rate & 0.175 & 0.170 & 0.102 \\
Its trended value & 0.433 & 0.415 & 0.193 \\
Economic power of organized & & & 0.068 \\
crime & 0.093 & 0.072 & 0.219 \\
\hline Its trended value & 0.282 & 0.220 & 0.038 \\
Intercept, Panel Model A & -0.695 & -0.309 & 0.066 \\
Numbercept, Panel Model B observations & -0.650 & -0.257 & 7896 \\
\hline
\end{tabular}


Figure A-1. Standard deviations of the income differential

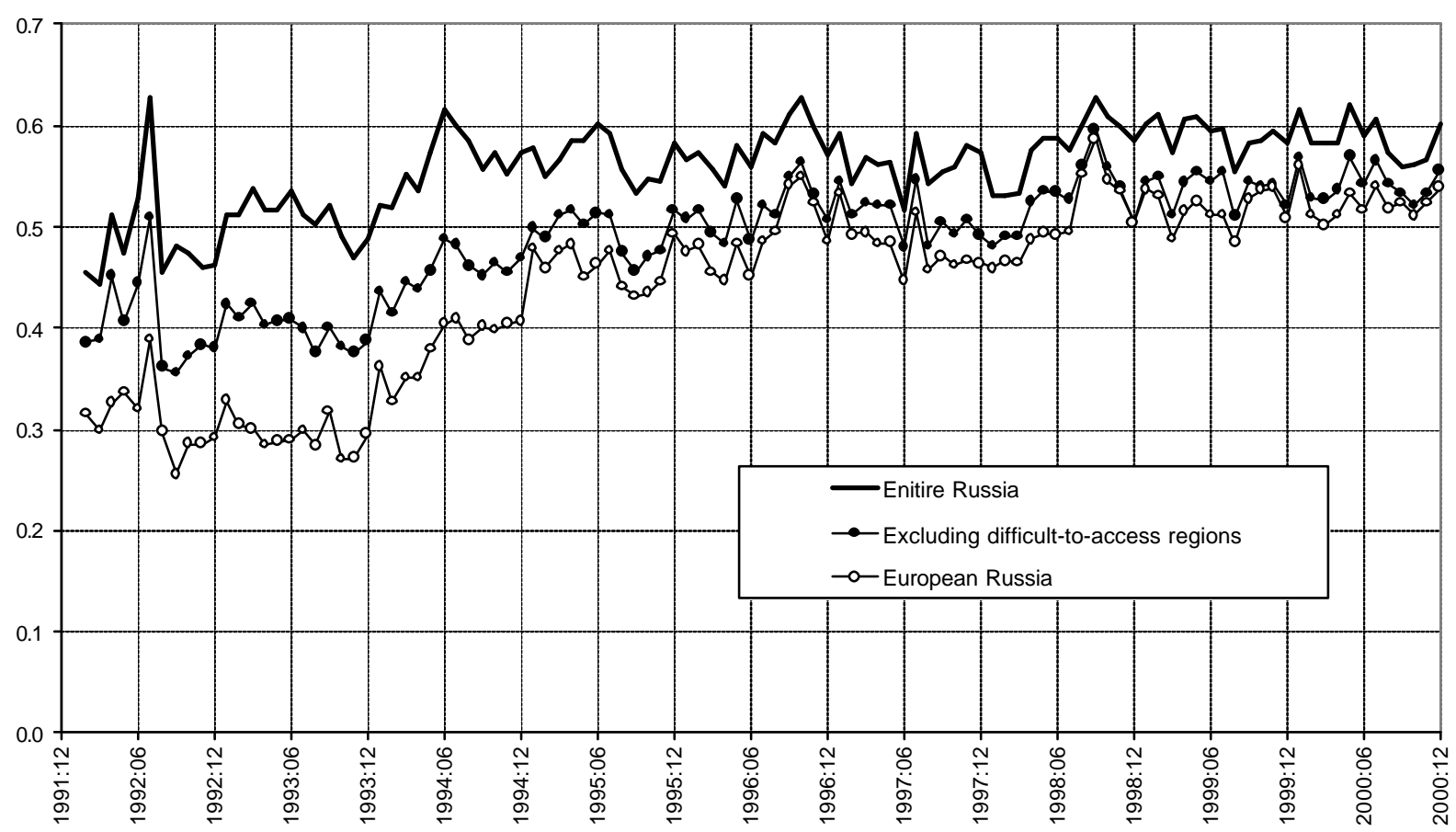

Figure A-2. Estimatres of the coefficient on distance

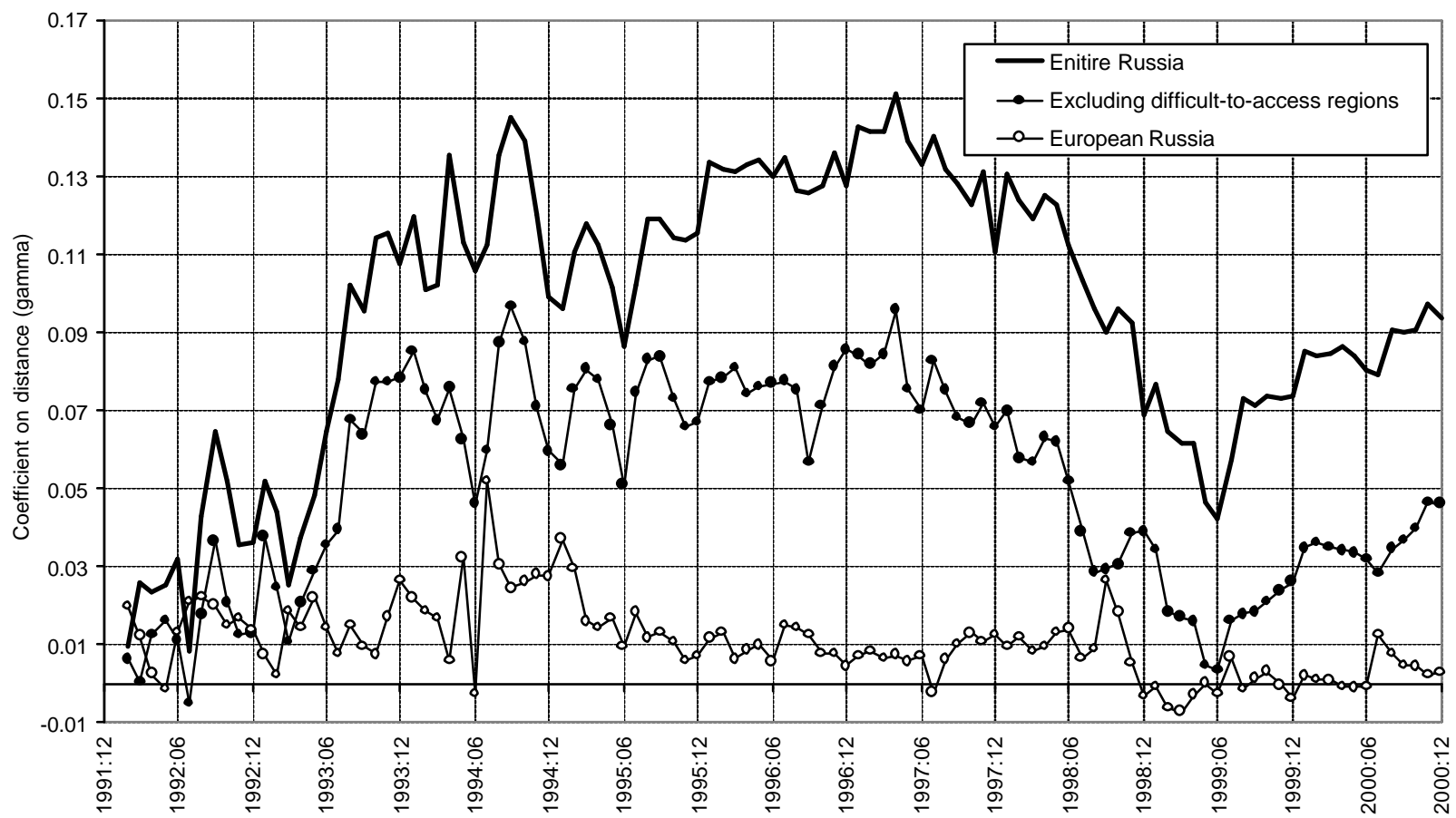


Figure A-3. The $\mathbf{R}$ squared statistic in the regressions reported

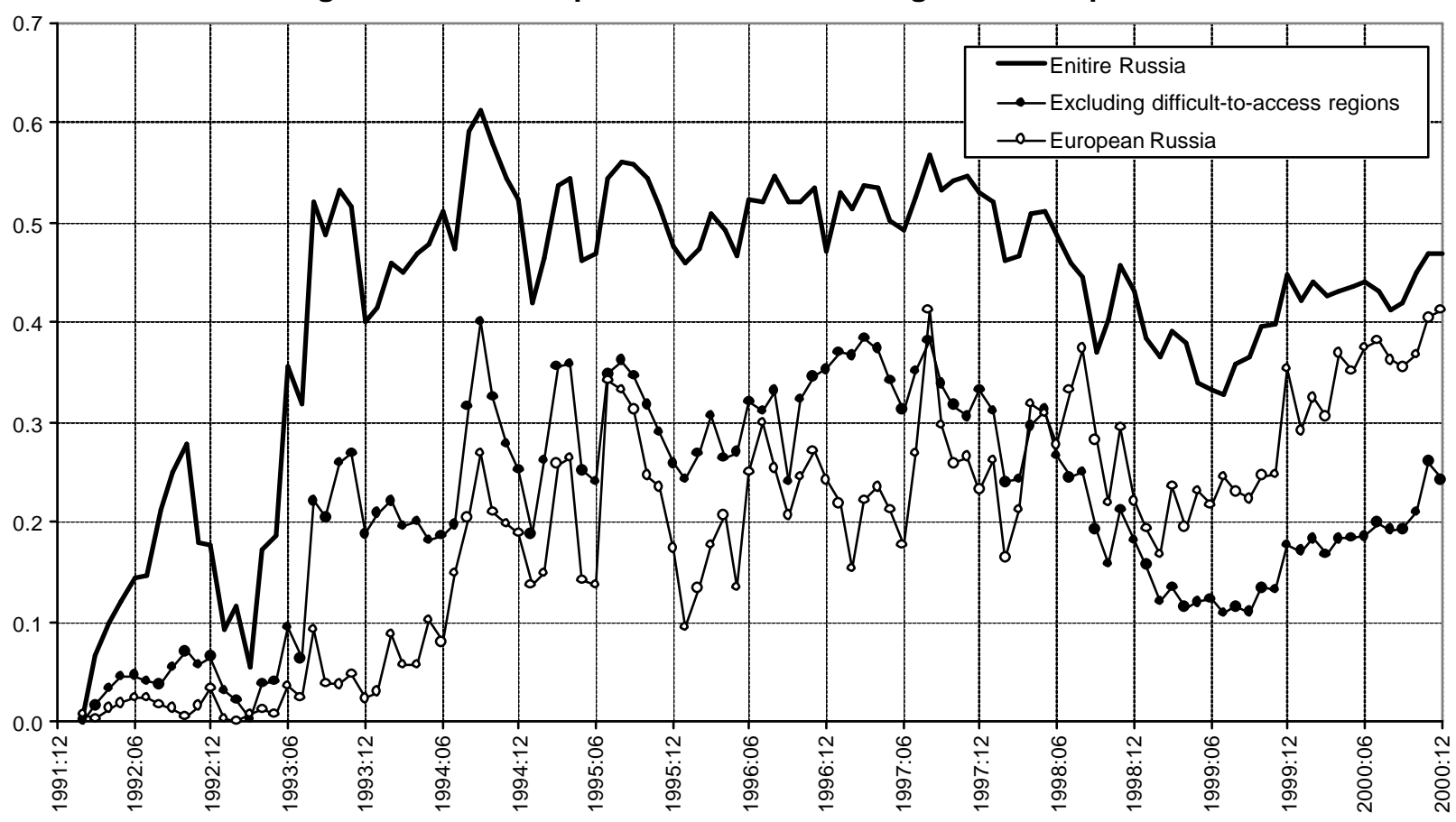

Figure A-4. Integration trajectories vs. infation and the $\$$ /rub. rate

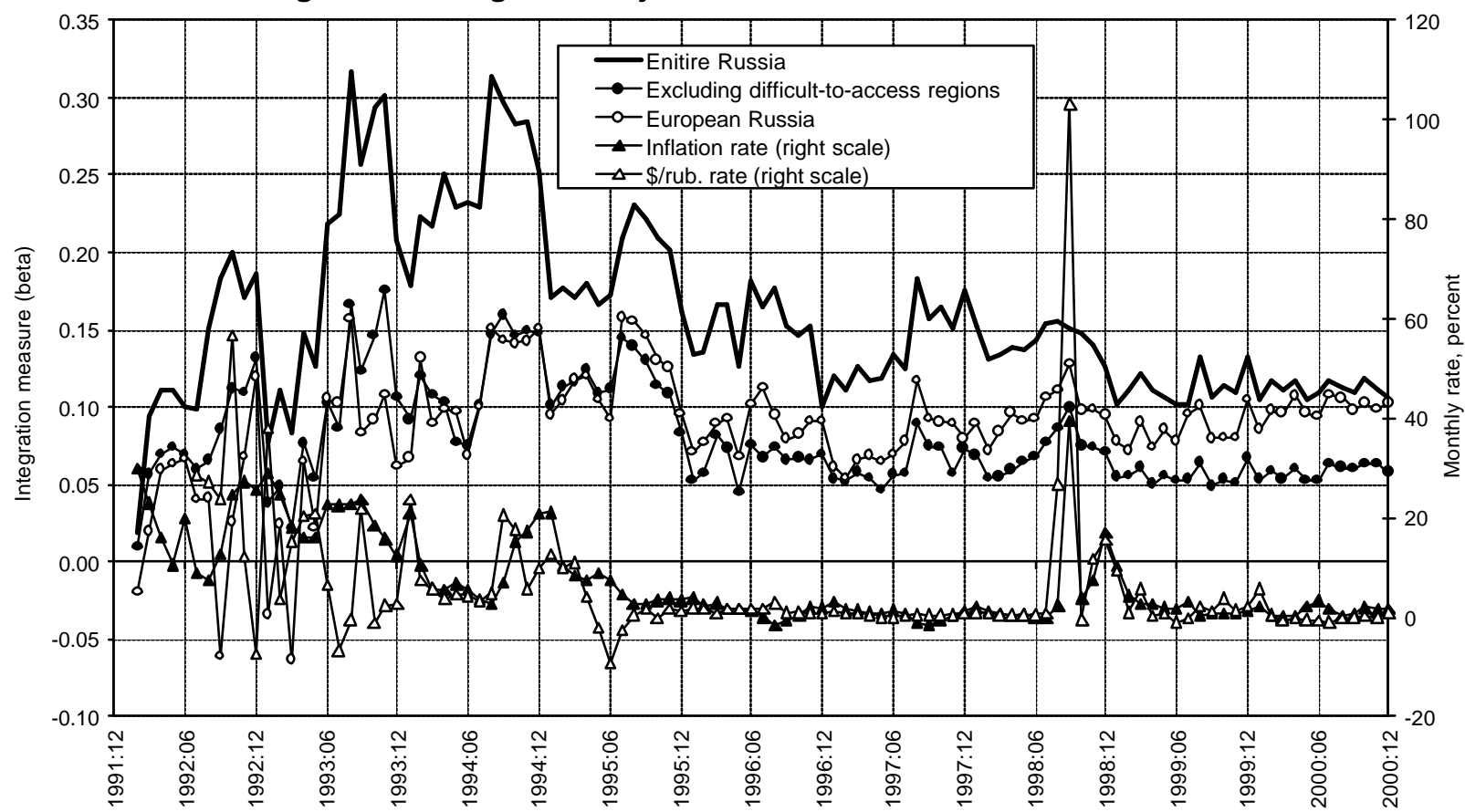


Figure A-5. Impact of the Moscow market

(a) on the integration measure

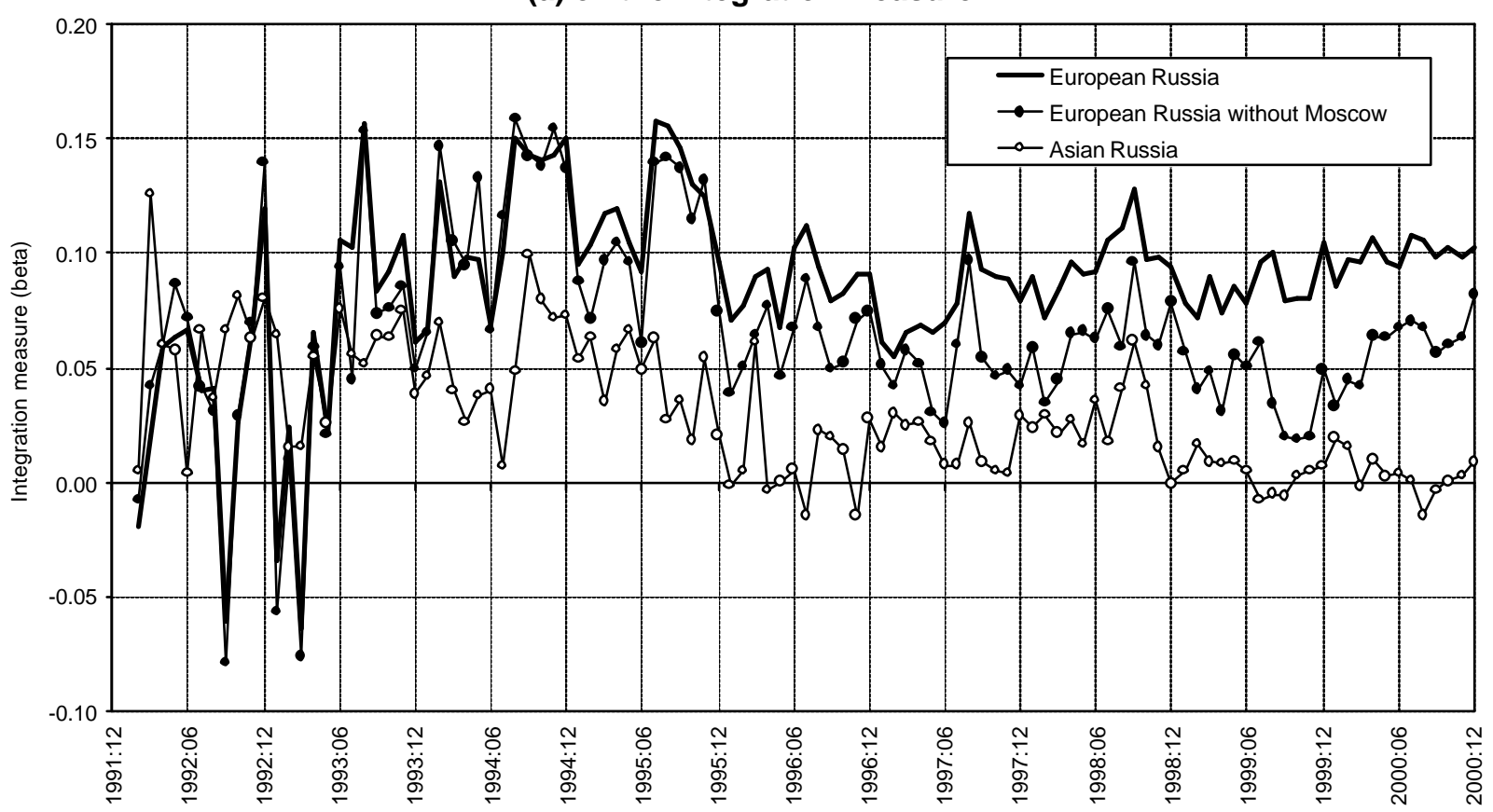

(b) on the coefficient on distance

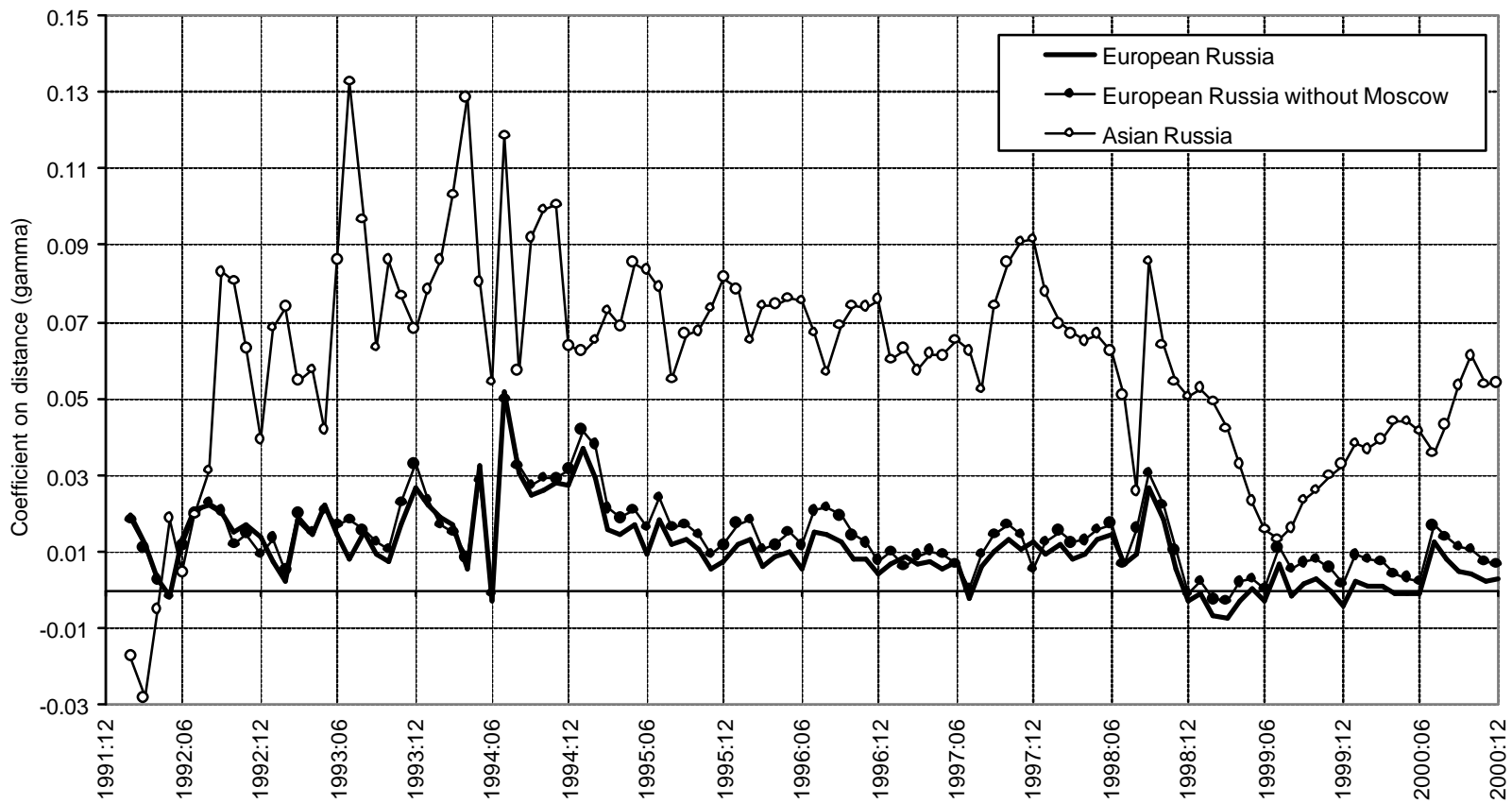


Figure A-6. Imact of filling the data gaps on integration trajectories

(a) Russia excluding difficult-to-access regions

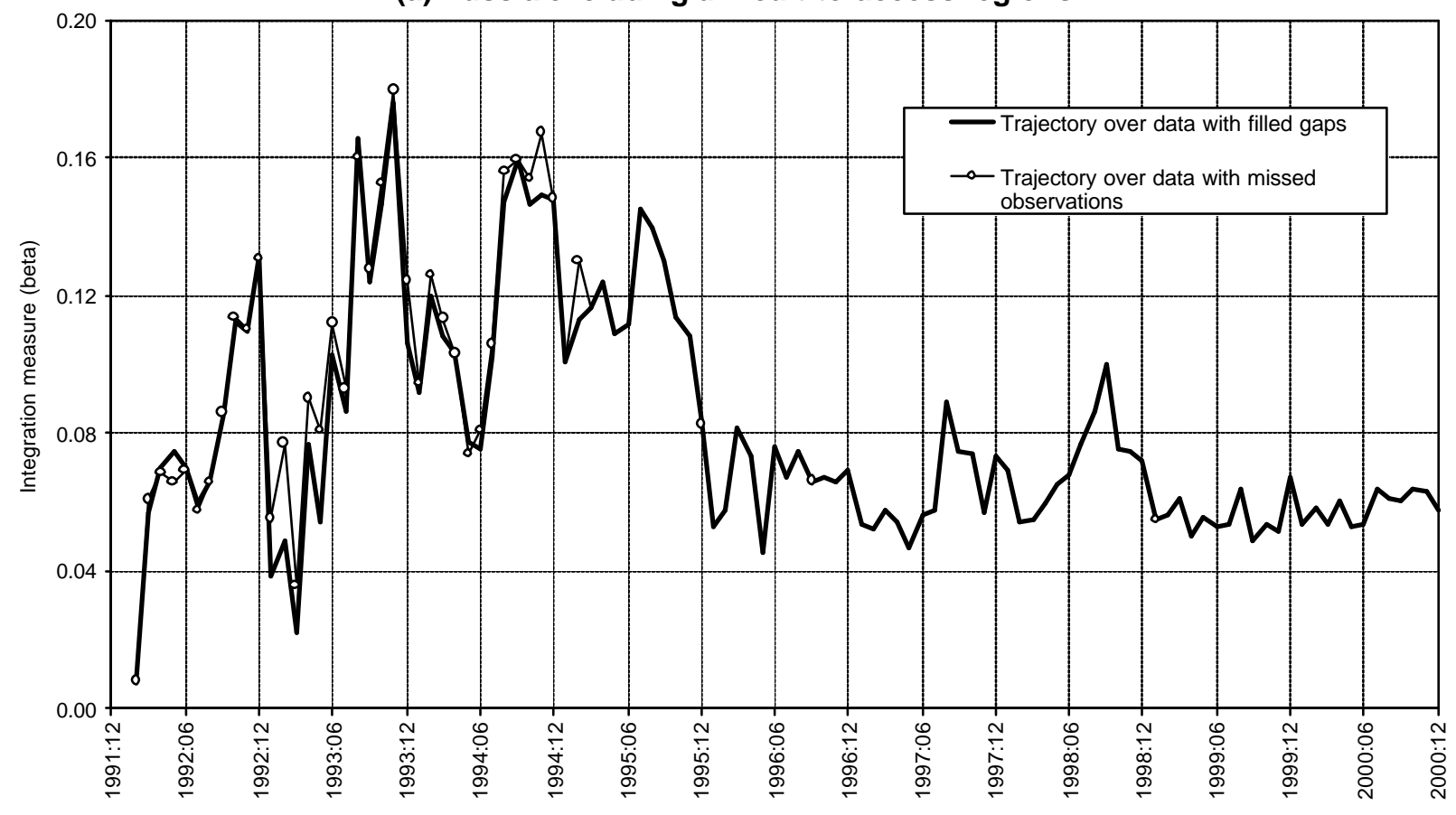

(b) European Russia

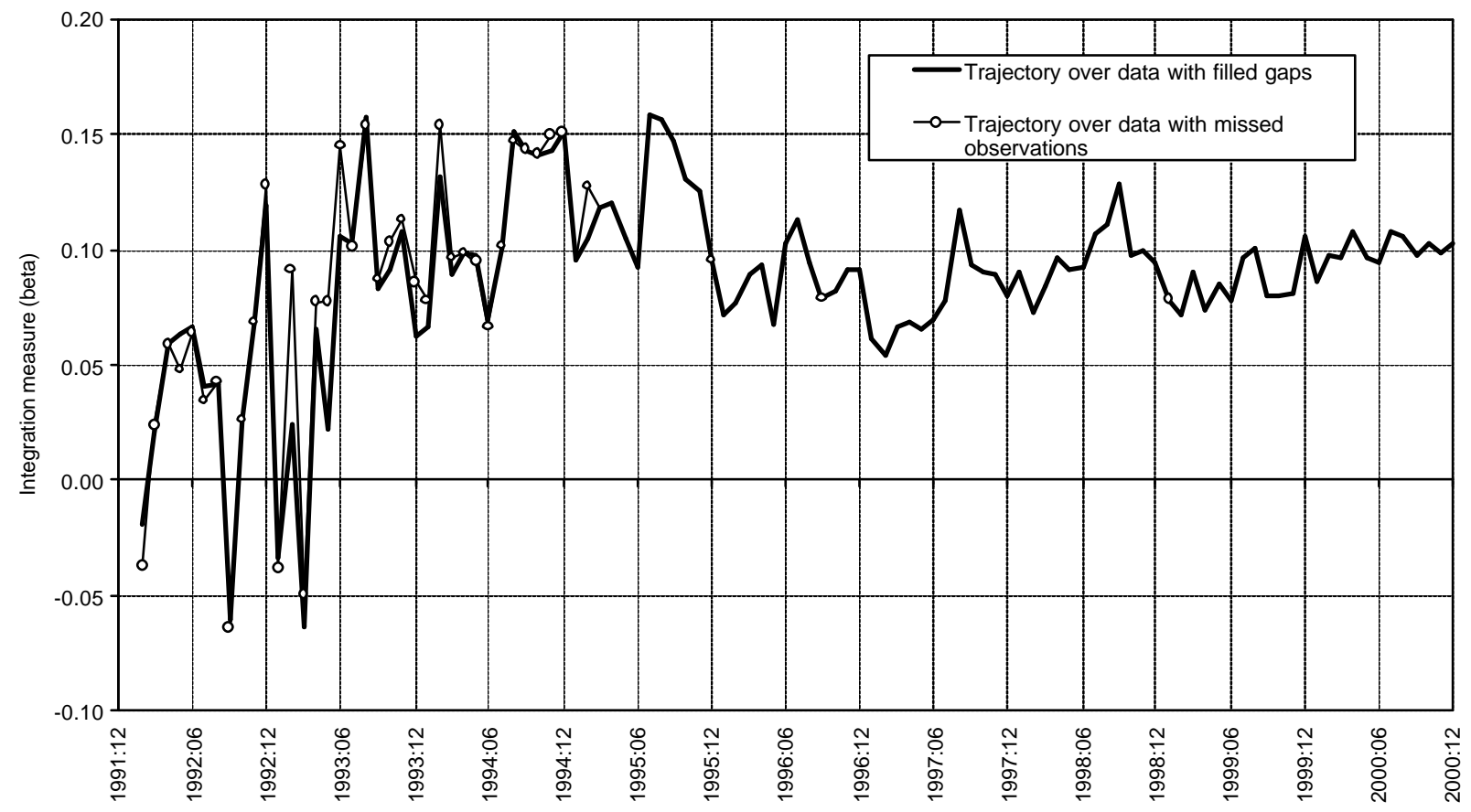


Figure A-7. Impact of the distribution costs variable on estimation results

(a) Entire Russia

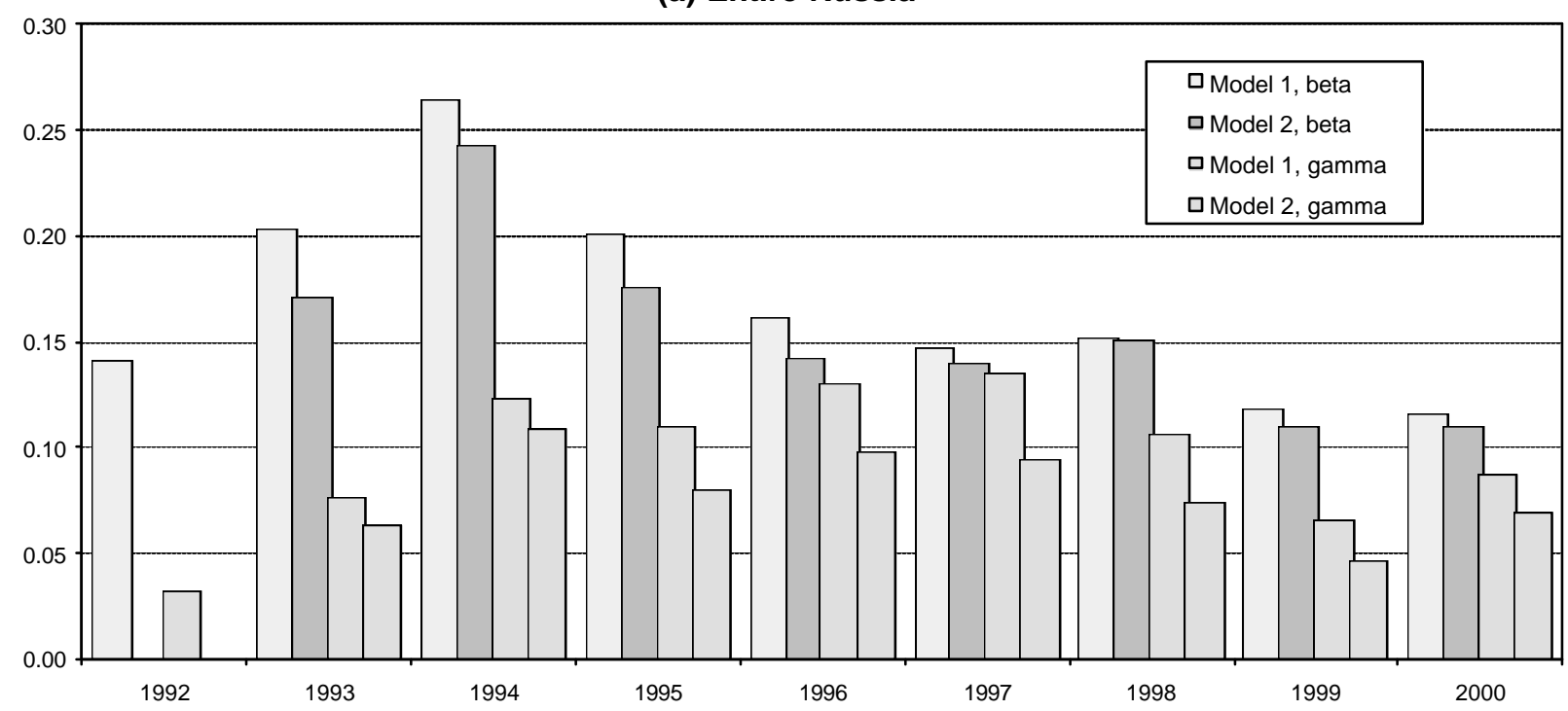

(b) Russia excluding difficult-to-access regions

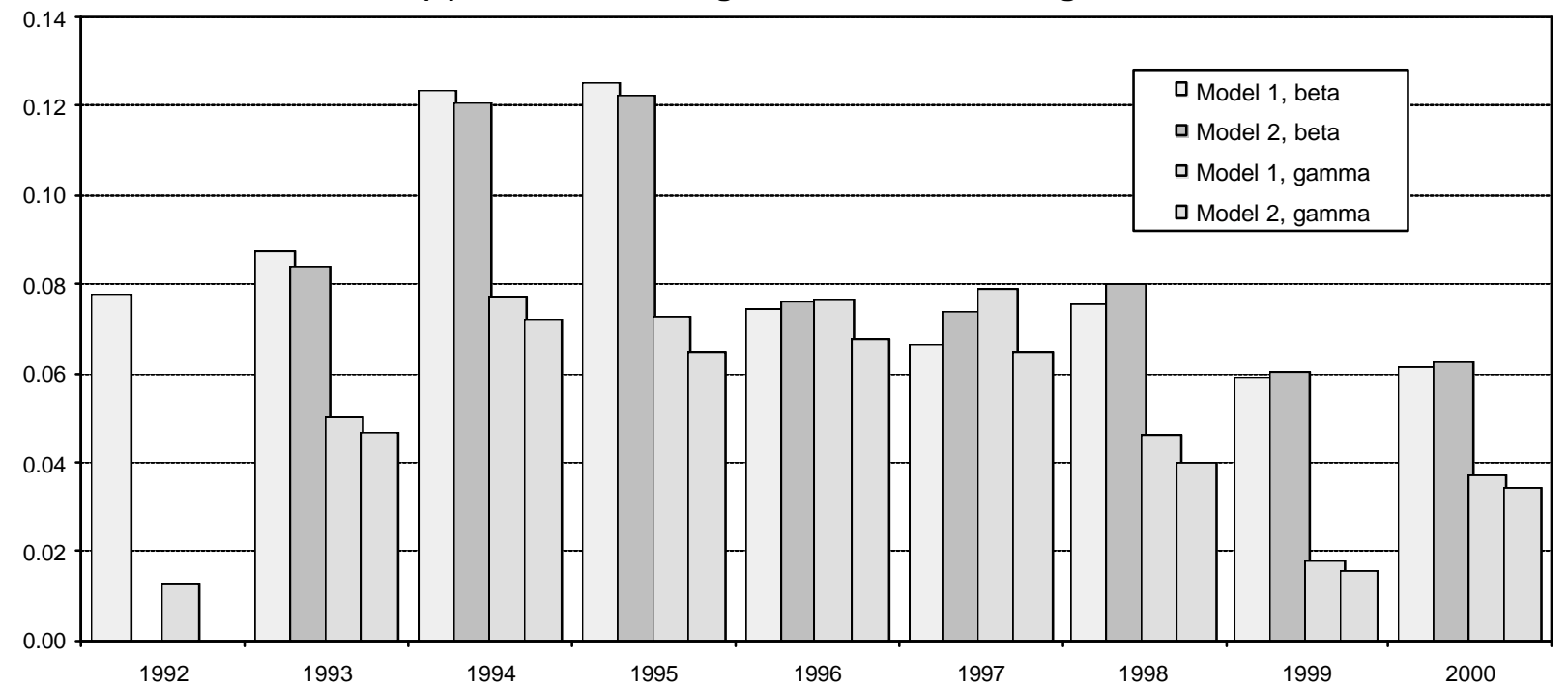

(c) European Russia

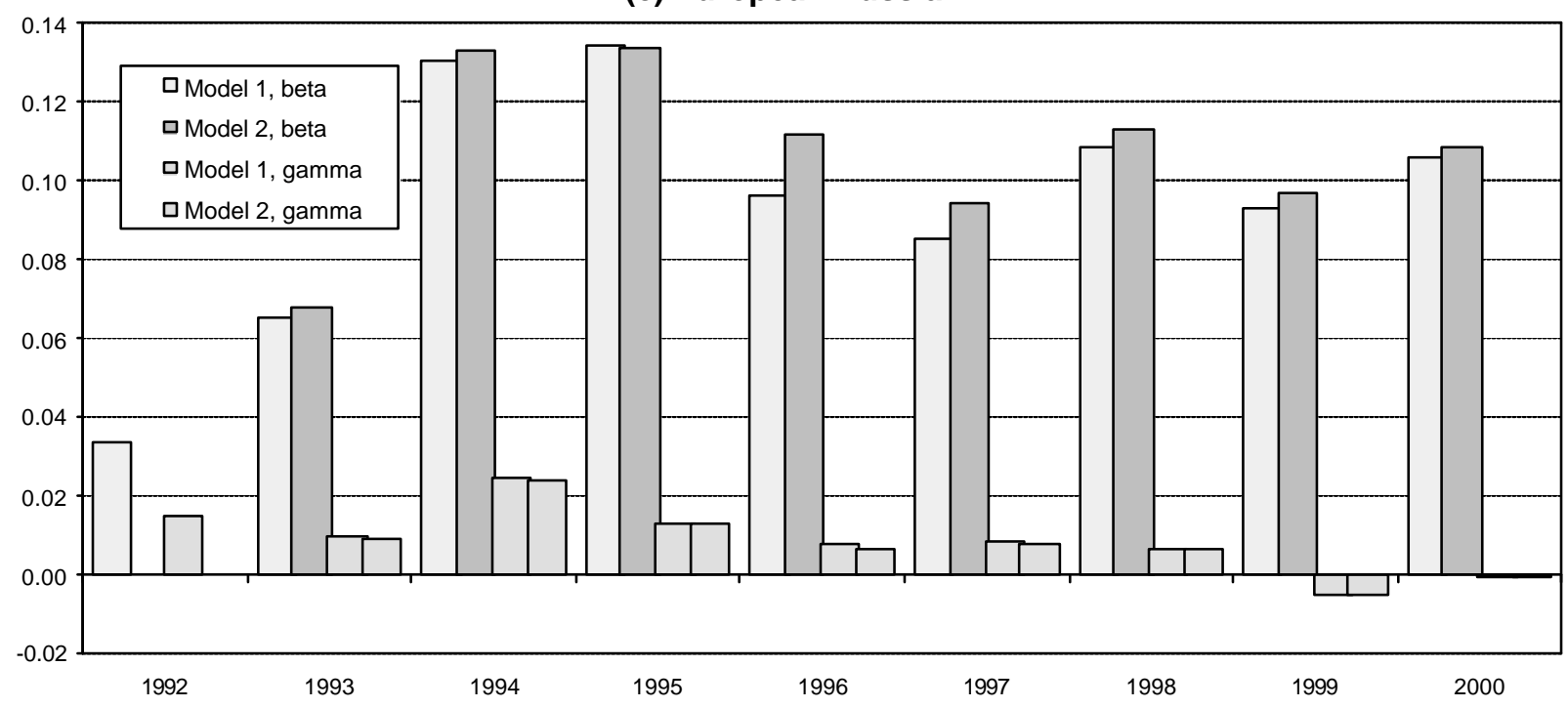


Figure A-8. Contributions of variables to:

(a) total price dispersion

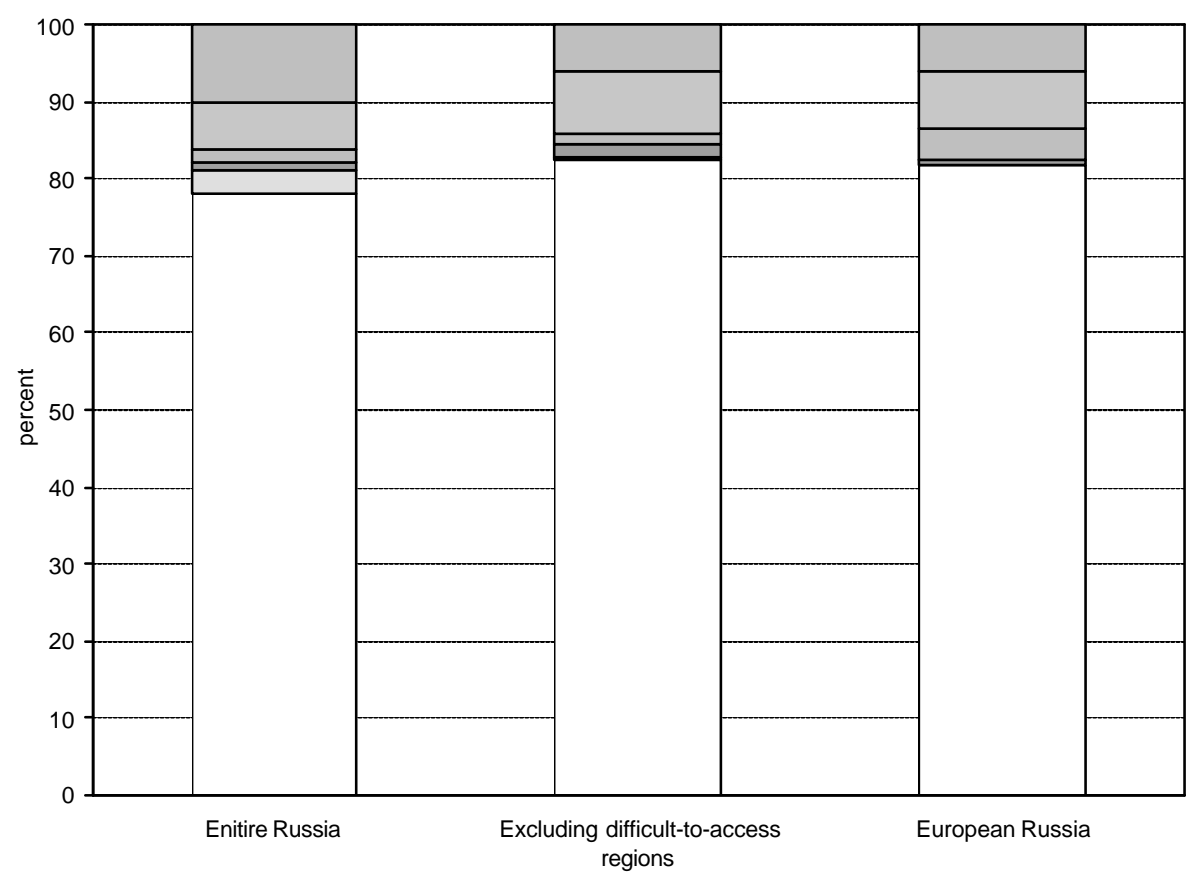

$\square$ Unidentified frictions

$\square$ Organized crime

$\square$ State intervention in economy

$\square$ Shipping conditions

$\square$ Distribution costs

$\square$ Distance

(b) price dispersion less the distance contribution

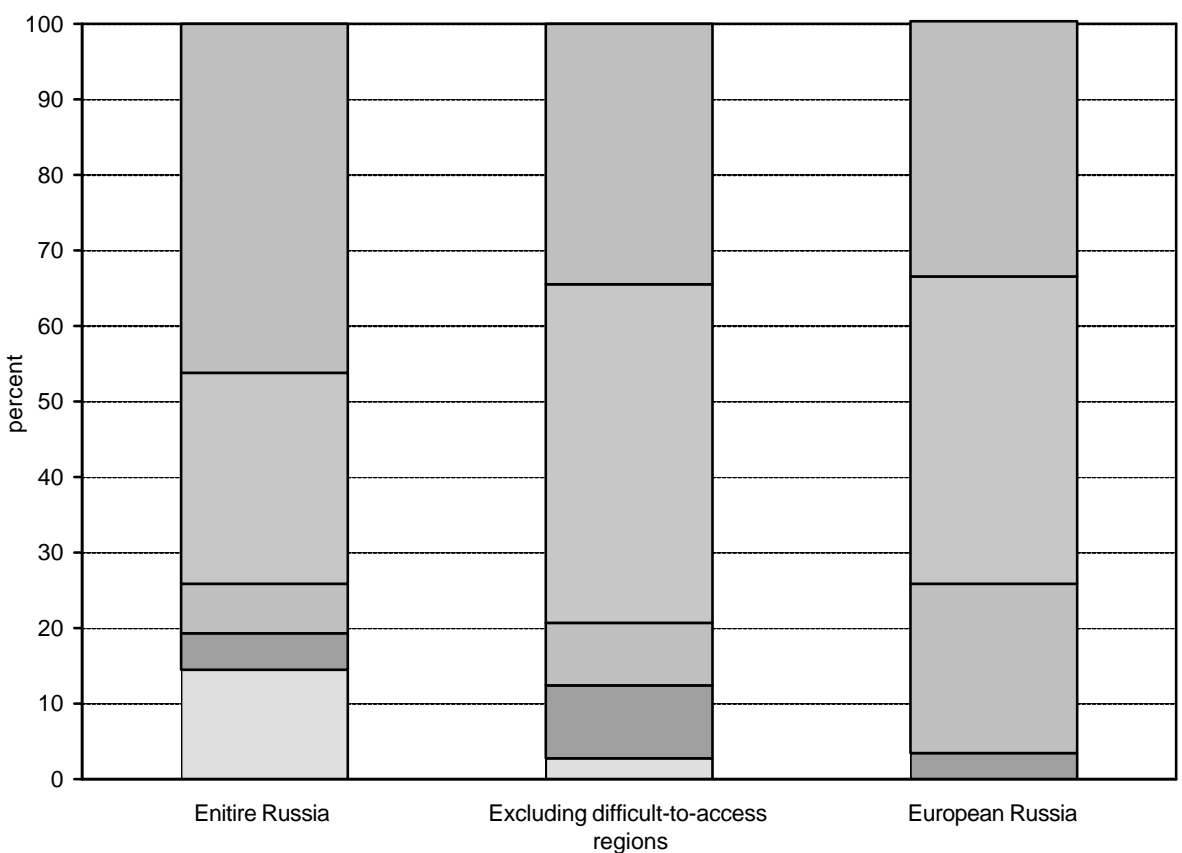

口Unidentified frictions

$\square$ Organized crime

$\square$ State intervention in economy

$\square$ Shipping conditions

口Distribution costs 
Author: Konstantin Gluschenko

Title: Market Integration in Russia During the Transformation Years

Reihe Ökonomie / Economics Series 116

Editor: Robert M. Kunst (Econometrics)

Associate Editors: Walter Fisher (Macroeconomics), Klaus Ritzberger (Microeconomics)

ISSN: $1605-7996$

(C) 2002 by the Department of Economics and Finance, Institute for Advanced Studies (IHS),

Stumpergasse 56, A-1060 Vienna • 正+43 159991 -0 • Fax +43 159991-555 • http://www.ins.ac.at 
ISSN: 1605-7996 